San Jose State University

SJSU ScholarWorks

Master's Theses

Master's Theses and Graduate Research

Fall 2010

\title{
Riparian Brush Rabbit Habitat Requirements in Caswell Memorial State Park
}

Clinton Robert Elsholz

San Jose State University

Follow this and additional works at: https://scholarworks.sjsu.edu/etd_theses

\section{Recommended Citation}

Elsholz, Clinton Robert, "Riparian Brush Rabbit Habitat Requirements in Caswell Memorial State Park" (2010). Master's Theses. 3857.

DOI: https://doi.org/10.31979/etd.h2rt-85uy

https://scholarworks.sjsu.edu/etd_theses/3857

This Thesis is brought to you for free and open access by the Master's Theses and Graduate Research at SJSU ScholarWorks. It has been accepted for inclusion in Master's Theses by an authorized administrator of SJSU ScholarWorks. For more information, please contact scholarworks@sjsu.edu. 


\title{
RIPARIAN BRUSH RABBIT HABITAT REQUIREMENTS IN CASWELL MEMORIAL STATE PARK
}

\author{
A Thesis \\ Presented to \\ The Faculty of the Department of Environmental Studies \\ San José State University \\ In Partial Fulfillment \\ of the Requirements for the Degree \\ Master of Science
}

by

Clinton Robert Elsholz

December 2010 
(C) 2010

Clinton Robert Elsholz

ALL RIGHTS RESERVED 
The Designated Thesis Committee Approves the Thesis Titled RIPARIAN BRUSH RABBIT HABITAT REQUIREMENTS IN CASWELL MEMORIAL STATE PARK

By

Clinton Robert Elsholz

APPROVED FOR THE DEPARTMENT OF ENVIRONMENTAL STUDIES

SAN JOSÉ STATE UNIVERSITY

December 2010

Dr. Lynne Trulio

Department of Environmental Studies

Dr. Rachel O’Malley

Department of Environmental Studies

Joanne Karlton

California State Parks 


\section{ABSTRACT \\ RIPARIAN BRUSH RABBIT HABITAT REQUIREMENTS IN CASWELL MEMORIAL STATE PARK \\ by Clinton Robert Elsholz}

With the rapid growth of agricultural and urban development in California's Central Valley in the $20^{\text {th }}$ and $21^{\text {st }}$ centuries, many habitats, including riparian forests, have been drastically altered. Along with these habitats, species that are dependent on them have also been fragmented and their long-term survival threatened. The riparian brush rabbit (Sylvilagus bachmani riparius) is one such species that has experienced profound population contraction over the past century. This research was conducted at Caswell Memorial State Park ("the Park"), located in Ripon, California, which is the largest remaining habitat fragment within the rabbit's historical range. One objective of this research was to characterize the vegetation of the Park which can be used as a model of suitable rabbit habitat. The Park was also surveyed for rabbit presence using motion sensor cameras and track plates. The relationships between vegetation and rabbit presence were evaluated and, although not statistically significant, the rabbit sites generally lacked high canopy, while blackberry and sedge were present. Strikingly, rabbits were found only at four sites $(n=125)$. Additionally, the two data collection methods used, motion sensor cameras and track plates, were evaluated on their effectiveness for detecting mammals within this habitat. This research showed that both methods were equally effective, although cameras proved to be superior for more practical reasons. 


\section{ACKNOWLEDGEMENTS}

I would like to express my sincerest gratitude to my thesis committee, Dr. Lynne Trulio, Dr. Rachel O’Malley, and Joanne Karlton for their insights, support and encouragement throughout the research process. I would also like to thank the College of Social Sciences at San Jose State University, California State Parks, and Pacific, Gas, and Electric for providing funding for this research. 


\section{TABLE OF CONTENTS}

INTRODUCTION...................................................... 1

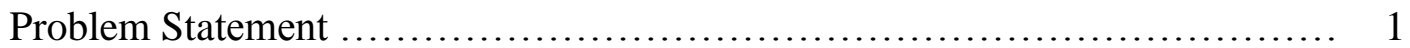

BACKGROUND: LITERATURE AND OBSERVATIONS................... 3

Habitat Fragmentation.................................................. 3

Mesopredator Release Theory.......................................... 4

Habitat Quality....................................................... 5

Scale and Home Range................................................. 6

Trail Proliferation and the Effects on Wildlife............................... 8

Status and Conservation of the Riparian Brush Rabbit....................... 10

Life History........................................................... 14

Caswell Memorial State Park............................................ 17

Research needs................................................. 25

Riparian brush rabbit......................................... 25

Track plates and motion sensor cameras-data collection methods........ 26

Research objectives............................................ 29

METHODS …............................................................... 31

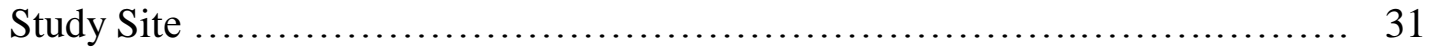

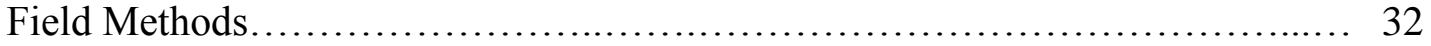

Analysis.......................................................... 33

RESULTS.......................................................... 34

RQ1 \& RQ2: Habitat Structures, Plant, and Animal Species.................... 34

RQ3: Habitat Characteristics of Sites Occupied by the Riparian Brush Rabbit... 50

RQ4: Methodology Comparison: Cameras and Track Plates................... 51

DISCUSSION ........................................................ 59

Comparison to Past Studies.............................................. 59

Trail Proliferation and the Rabbit........................................ 60

Flood Regime ........................................................ 61

The Park and Mesopredator Release Thoery............................. 64

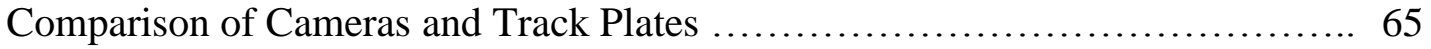

Study Recommendations............................................. 66

Management Recommendations...................................... 69

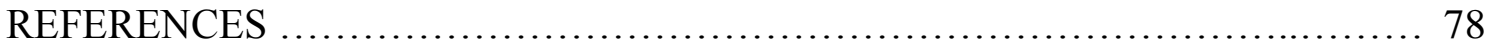




\section{LIST OF TABLES}

Table 1. Summary of Live-Trapping Surveys, 1998-2008...................... 22

Table 2. Definition of Vegetation Layers.................................. 32

Table 3. Habitat Structures Defined by the Presence of Vegetation Layers ......... 35

Table 4. Plant Composition and Cover Across All Sites ........................ 37

Table 5. Plant Composition and Cover for Structure A....................... 38

Table 6. Plant Composition and Cover for Structure B......................... 39

Table 7. Plant Composition and Cover for Structure C........................ 40

Table 8. Plant Composition and Cover for Structure D......................... 41

Table 9. Plant Composition and Cover for Structure E......................... 42

Table 10. Animal Species Presence by Habitat Structure ........................ 43

Table 11. Five Most Common Plant Species within Each Habitat Structure.......... 44

Table 12. Comparison of Vegetation Species Present at Sites Occupied by All Animal Species.................................................. 51

Table 13. Habitat Characteristics of Sites Where the Rabbit Was Found............ 51

Table 14. Cameras (Cam) and Track Plate (TP) Comparisons Measured by Catch Per Unit Effort (CPUE) for the Rabbit, Fox, Raccoon, and Opossum..... 52

Table 15. Cameras (Cam) and Track Plate (TP) Comparisons Measured by Catch Per Unit Effort (CPUE) for the Squirrel, Rat/Mouse spp., and All Species. 53 


\section{LIST OF FIGURES}

Figure 1. Historical Range of the Riparian Brush Rabbit....................... 13

Figure 2. Study Site: Caswell Memorial State Park.............................. 18

Figure 3. 1957 Aerial Photograph of Caswell Memorial State Park................. 23

Figure 4. 2009 Aerial Photograph of Caswell Memorial State Park................ 24

Figure 5. Map of Structure A Understory Plant Species Proportional Cover by Site.......................................................... 45

Figure 6. Map of Structure B Understory Plant Species Proportional Cover by Site......................................................... 46

Figure 7. Map of Structure C Understory Plant Species Proportional Cover by Site.......................................................... 47

Figure 8. Map of Structure D Understory Plant Species Proportional Cover by Site.......................................................... 48

Figure 9. Map of Structure E Understory Plant Species Proportional Cover by Site.......................................................... 49

Figure 10. Map of Gray Fox Presence ...................................... 54

Figure 11. Map of Raccoon Presence ....................................... 55

Figure 12. Map of Opossum Presence....................................... 56

Figure 13. Map of Western Gray Squirrel Presence............................ 57

Figure 14. Map of Rat/Mouse Presence ..................................... 58

Figure 15. Potential High Water Refugia, "Bunny Mounds," Sites ................. 77 


\section{Introduction}

\section{Problem Statement}

Over the past century, ecosystems have been severely altered and fragmented throughout the Central Valley region of California, threatening the existence of many species such as the San Joaquin kit fox (Vulpes macrotis mutica), the blunt nosed leopard lizard (Gambelia silus), and the riparian brush rabbit (Sylvilagus bachmani riparius) (United States Fish \& Wildlife Service (USFWS), 1998). As urban development in this region increases to meet population demands, protection for these threatened species is more critical than ever before. For many species, habitat loss is threatening their survival (Meffe \& Carrol, 1997), and understanding habitat requirements is essential to protecting and recovering each species. Unfortunately, wildlife managers often lack adequate knowledge of species' habitat requirements to effectively protect and recover many of these species. When adequate data do not exist, wildlife managers must either attempt to collect the required information through research or make partially-informed decisions.

In addition to urban development, the landscape in California's Central Valley is fragmented by agricultural fields and degraded by invasive species populations, which are reducing native communities to small patches of habitat (Schoenherr, 1992). Consequently, a species' likelihood of extinction greatly increases when its ability to find essential resources are severely hampered (MacArthur \& Wilson, 1963). Small populations can lead to a reduction in genetic diversity, which can further threaten the population's persistence. Restoring native habitat will provide depressed biological populations with the opportunity to exploit more abundant resources and connect isolated 
populations with one another. In addition, environmental restoration is an essential step in the process of reestablishing native populations on degraded lands. These measures are imperative to the recovery of small populations. However, the success of a restoration and species recovery project depends on acquiring adequate habitat data on the species of concern. 


\section{Background: Literature and Observations}

\section{Habitat Fragmentation}

Island biogeography theory (MacArthur \& Wilson, 1967) is a foundation

principle in the conservation biology field. This theory describes the relationship between islands, which are habitat fragments of species diversity. Species need appropriate habitat to survive, and loss of this habitat imposes negative effects on populations. This theory reaches beyond habitat quality as an influential factor of populations and is inclusive to fragment size, shape, and isolation as well. From island biogeography theory we can predict that smaller areas of habitat lead to greater risk of extinction for a particular species. When larger habitat areas exist, a greater abundance of resources are available, supporting larger populations (Fahrig \& Merriam, 1994; MacArthur \& Wilson, 1967; Meffe \& Carrol, 1997).

Fahrig and Merriam (1994) outlined a variety of habitat attributes that should increase population persistence on the landscape level. In 1985, they built a model to test the effect of fragment isolation on populations, confirming the negative effects. Fahrig and Merriam's (1994) study investigated not only the importance of the size of a fragment but also their shapes and spatial configurations. They concluded that closer proximity and greater sizes of patches strengthen conservation plans, thus leading to a greater chance of creating a metapopulation of a species. They also explained that these considerations are most crucial for endangered species that have often been listed because of habitat loss. This is supported by Bond, Wes Burger, and Leopold's (2000) findings that cottontail rabbits with greater movement ranges are subject to higher rates of 
predation. Larger habitat patches with good quality habitat, then, can be expected to reduce the open exposure of rabbits and lower predation rates.

\section{Mesopredator Release Theory}

A possible explanation or contributor to the decline of the riparian brush rabbit is the increased numbers of mesopredators. The mesopredator release theory states that the absence of a top predator results in an increased abundance in secondary level predators which in turn has a negative effect on the prey base (Crooks \& Soule, 1999; Rogers \& Caro, 1998; Schmidt, 2003). It is widely accepted that top predators require very large geographic areas to gather the required resources to support their populations. As native habitat is rapidly converted to other uses, it becomes fragmented and top predators are less able to find the resources needed to sustain population levels. Further, these alterations are usually incompatible or even hostile to these species and become a barrier to their movement leading to even greater downward pressure on their population. In the absence of these top predators, mesopredator populations are no longer suppressed and are allowed to increase either due to less competition or a lack of direct predation. As a result of the mesopredator population increase, their prey base is consumed at a more rapid rate than before, resulting in a downward pressure on these lower level species populations and creating opportunities for other, more adaptable species.

Crooks and Soule (1999) found that the decline of the coyote, combined with the effects of habitat fragmentation, resulted in the release of the secondary predators and decreases in song birds. More specifically, they determined that coyote presence was negatively correlated with habitat fragmentation size. Within the fragments where coyote 
was absent, raccoon and opossum populations were greater and bird populations were lower. In other words, coyote presence was a predictor of bird populations. Findings by Rogers and Caro (1998) also support this theory. They predicted and confirmed that 1) the presence of coyotes would be positively correlated with song bird nests and 2) predation of nests would be positively correlated with mesopredator presence. Schmidt (2003) used data spanning 20 years and a large area, the state of Illinois, to test the mesopredator theory. He was able to establish the vulnerability of low nesting birds to raccoon predation.

\section{Habitat Quality}

Habitat characteristics often play a major role in the distribution of animals, especially specialist species. Specialists, by definition, inhabit areas that have a narrow range or specific habitat attributes. Therefore, knowledge and replication of these habitat attributes are required before the specialist species can inhabit new areas. If the rabbit is a specialist, a thorough understanding of its habitat requirements is critical to avoid wasting scarce management funds. Morris (1996) explains that specialists emerge when habitats are "coarse-grained," meaning there are large patches of habitat, rather than "fine-grained," where many small patches of different habitat types exist. Specialists are restricted to specific habitats and, therefore, the cost of traveling through undesirable habitat, necessary in a fine-grained environment, would be prohibitive (Danielson, 1991). It would then seem that generalists are less likely to thrive in these "coarse-grained" types of habitat. In order for the generalist to turn this "coarse-grained" habitat into "fine- 
grained" habitat, it must increase its range. An added advantage of increasing the species territory becomes the ability to use habitat that is unused or underused by other species.

In addition to habitat size, studies have found that habitat quality is an influential factor explaining mammal distribution (Danielson, 1991; Fahrig \& Merriam 1994). Habitat quality can often determine whether an area is either a source or a sink habitat (Danielson, 1991). Source habitat is defined as habitat that can support a surplus of individuals and results in positive reproductive output, and, conversely, habitat that reduces a population is considered sink habitat. If a landscape has too much sink habitat, then populations will decrease. Further, the duration of time lapsed while an individual investigates and eventually rejects habitat can be costly. For example, Danielson (1991) found the duration of sampling time by a vole was 14 days in sink habitat, whereas an area of the same dimension in source habitat was covered in less than two days. Consequently, it is critical that sink habitat is limited due to the energy and reproductive costs to the mammal.

\section{Scale and Home Range}

Determining the appropriate scale of a study is important since the scale will often have a major effect on the data obtained from the study. For example, small study sites may exclude important habitat characteristics, while large study sites demand time and resources. To illustrate this point, two articles provide data on the same volcano rabbit (Romerolagus diazi) population in relation to its habitat use. Fa, Romero, and Lopez-Paniagua (1992) used a coarse-filter or large-scale approach to study the rabbits in Mexico by dividing the distribution range into four vegetation types mainly based on tree 
species. Velazquez and Heil (1996) used a fine filter approach and divided the vegetation classification into thirteen different categories. While limitations existed in both studies, Velazquez and Heil (1996) were better able to detect statistically significant details regarding the rabbit's habitat than $\mathrm{Fa}$ et al. (1992).

Danielson (1991) also addresses the issue of scale, warning of the dangers of narrowing a study to such a small degree that the end result overlooks important components of the landscape, e.g., source or sink habitat. To alleviate this problem in determining the proper scale for study, Danielson (1991) advocated for the use of a multiscale approach, which lead to the understanding of the "correct" scale. Manning and Edge (2004) conducted a multi-scale study that examined the interactions of small mammals, vegetation, downed wood, and habitat heterogeneity. Their study consisted of three levels: trap sites, 1-hectare forest patches, and forest stands. They found a positive correlation between deer mice (Peromyscus maniculatus) and downed wood, while the correlation between the creeping vole (Microtus oregoni) and downed wood was negative. Downed wood varied within patches, but not among patches. This suggests that the appropriate scale to study these small mammals is 1-hectare patch. Morris (1996) found that variation existed within the small mammal distribution when plotting the data from the two scales.

If the home range of a species can be determined, the appropriate scale of a study becomes much clearer. Chapman and Litvaitis (2003) state that Sylvilagus spp. home ranges are difficult to define because they do not maintain territories, yet the authors also indicated that S. bachmani ranges are tied to habitat type, and more specifically to 
patches of Rubus spp. The study by Zollner, Smith, and Brennan (2000) on Arkansas swamp rabbits' (S. aquaticus) movements during inundation may possibly be used to decipher the rabbit home range. This study used radio telemetry to track the swamp rabbits and found that all of the rabbits collared used different habitat during inundation, usually escaping to higher ground. This underlines the importance of topography variability and adequate habitat to support the population after colonization of the new habitat. This study concluded the rabbit's home range was between $0.75-2.0$ ha and determined high ground was a critical habitat element.

Basey (1990) studied riparian brush rabbits within an area of Caswell Memorial State Park (the Park) where he had frequently observed rabbits. He set up ten transects with traps spaced five meters apart. He found males had a significantly larger home range $\left(957 \mathrm{~m}^{2}, \mathrm{SD}=843, \mathrm{n}=3\right)$ than females $\left(244 \mathrm{~m}^{2}, \mathrm{SD}=97, \mathrm{n}=7\right)$. The longest linear distance moved by a rabbit was $90 \mathrm{~m}$ and the density of rabbits was $1.5-3.0 /$ ha.

\section{Trail Proliferation and the Effects on Wildlife}

The behavioral responses of animals to human disturbance can be varied. Some animals avoid human activity while others habituate or ignore the activity. Even still, others can be attracted to the presence of humans (Whittaker \& Knight, 1998). Each response has advantages and disadvantages depending on the recreational activity. For example, in areas used by hikers, animals can become habituated allowing them continued use of the habitat. On the other hand, if the area is also used for hunting, habituation could make the animal more vulnerable. In situations where the recreation activity is non-consumptive, the avoidance behavior can result in consequences to the 
individual and the population. Constant disruption can stress an animal (MacArthur, Geist, \& Johnston, 1982) and lead to lower reproduction rates (Yarmoloy, Bayer, \& Geist, 1988). Further, if the animal flees or avoids areas near trails, then they are not utilizing all of their potential home range (Whittaker \& Knight, 1998; Yarmoloy et al., 1988) and limited habitat and are reduced further. Several studies have documented the avoidance response in a range of species. Taylor and Knight (2003) measured the responses of mule deer, bison, and pronghorn antelope to hiker and bicyclist presence and found a $70 \%$ chance of these species avoiding interaction by fleeing when they were within $100 \mathrm{~m}$ of the intruder. In a different study, researchers compared the behavioral responses of bighorn sheep to the presence of hikers, mountain bikers, and vehicles and found the animals flee more frequently in the presence of hikers (Papouchis, Singer, \& Sloanal, 2001). Both of these studies demonstrate that hikers can alter an animal's behavior.

Sauvajot, Buechner, Kamradt, and Schonewald (1998) measured vegetation, small mammals, and birds between "disturbed" sites, as measured by the presence of roads and trails, and "intact" sites, those sites with minimal roads and trails. They found that vegetation and small mammal species differed between the two treatments, noting "disturbed" sites as having less woody vegetation, more forbs, and shorter vegetation height. Consequently, they found that the small mammal species found within the "intact" sites were more specialized than the small mammal species in the "disturbed" sites. This study indicates a shift in species composition correlated with trail presence. Whittington, St. Clair, and Mercer (2005) found that wolves avoided areas with dense 
trail and road networks and high human use. They did note, however, that the wolves' behavior changed where human presence was low by actually using the trails as travel corridors. Thiel (1985) also reported a correlation between wolf population declines and increasing road density in Wisconsin.

Many studies have focused on bird behavior and their response to trails and human presence. Riffell, Gutzwiller, and Anderson (1996) studied the effects of a solitary hiker on bird richness and abundance for five years and found only between year declines of common species that did not persist into subsequent years. Miller, Knight, and Miller (1998) found bird species composition varied depending on the proximity to a trail. Specialist species were found further away from trails and absent within $75 \mathrm{~m}$ of the trail and replaced by generalist bird species. The researchers also reported higher rates of nest predation near the trails.

\section{Status and Conservation of the Riparian Brush Rabbit}

The riparian brush rabbit (rabbit) is a species dependent on Central Valley riparian communities and is endangered by habitat loss and fragmentation. Schoenherr (1992) estimated that the 400,000 ha of Central Valley riparian forest existing in the 1800s has been reduced to less than 40,000 ha. Considered to be some of the most diverse habitats in the state, riparian forests have largely been converted to agricultural use due to the Central Valley's cheap and fertile land, inexpensive water, and government subsides (Schoenherr, 1992). In addition, altered flooding regimes due to dam construction have likely contributed to the decline in the riparian woodlands (Schoenherr, 1992). Consequently, the rabbit population has constricted to less than $5 \%$ of its 
historical range (USFWS, 1998). The remaining habitat fragments available to the rabbit are confined within levees and are susceptible to long periods of flooding. Also, the intensification of agricultural development, such as the transformation of hedgerows and feral fields into economically productive lands are creating a hostile, inhabitable landscape for the rabbit (Chapman \& Litvaitis, 2003).

The riparian brush rabbit was listed as endangered by the state and federal governments in 1994 and 2000, respectively. The recovery strategy for the rabbit is outlined in Recovery of Upland Species in the San Joaquin Valley, California (USFWS, 1998). Presently, there are two known natural populations left, one at Caswell Memorial State Park and one on private property known as Paradise Cut. Riparian brush rabbit conservation efforts have primary concentrated on establishing a new population within the rabbit's historical range (Figure 1). In 2001, a captive breeding and reintroduction program was undertaken and individuals were released at the San Joaquin River National Wildlife Refuge (the Refuge) (Hamilton, Kelly, Williams, Kelt, \& Wittmer, 2010). The Refuge had been used for agriculture for most of the 1900s and was purchased by the United States Fish and Wildlife Service in 1986. Currently, the habitat consists of patches of remnant and restored riparian vegetation (Rentner \& Lloyd, 2010). From 2002-2005, 325 rabbits were released at the Refuge. All but one was fitted with a radio collar. Of the 324 monitored rabbits, 283 individuals were radio collared until their death (Hamilton et al., 2010). Within 12 weeks of being released, 53\% $(n=149)$ of the rabbits died. Although the cause of most deaths were unknown (62.9\%), predation accounted for one-fourth of known causes of mortality (Hamilton et al., 2010). Within the floodplains 
of the Refuge, managers have also created large, elevated mounds of soil and planted them with native plant species to provide the rabbit with high water refugia. This effort was in response to the 2006 flood event that resulted in the loss of $95 \%$ of radio collared rabbits at the Refuge (P. A. Kelly, personal communication, July 9, 2010). Live-trapping efforts conducted in the Spring of 2010 indicated rabbits occupied the mounds during a period without flooding (Rentner \& Lloyd, 2010).

Although great strides have been made regarding rabbit conservation, such as the first steps in the establishment of an additional population, their habitat requirements are still poorly understood. Habitat information can help managers with preservation and recovery efforts because restoration of habitat remains a top priority (USFWS, 1998). The opportunity to study the rabbit's habitat needs in its natural environment is limited to Caswell Memorial State Park since the only other known natural population, at Paradise Cut, is on private land where access is restricted. 


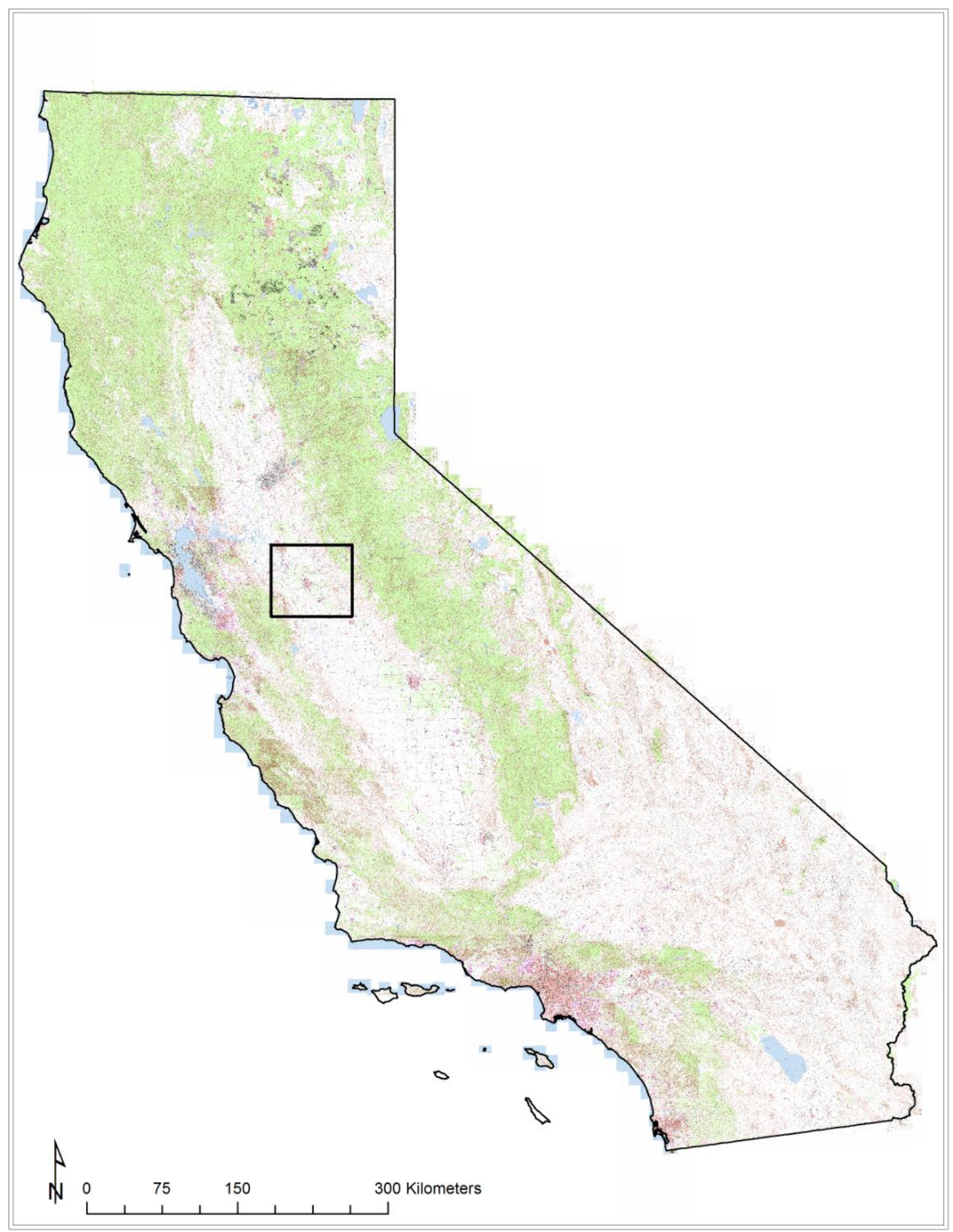

Figure 1. Historical Range of the Riparian Brush Rabbit. The rabbit once lived within the riparian forests along the Stanislaus, Tuolumne, and San Joaquin rivers in the Central Valley (USFWS, 1998). Note. ArcMap 9.3 software was used to generate this map. 


\section{Life History}

The riparian brush rabbit is one of 13 subspecies of brush rabbit found west of the Sierra Nevada mountain range. This small cottontail is brownish in color with a white underside. An adult is typically between 300 to 375 millimeters in length and can be distinguished from other cottontails by its protruding cheeks, uniform ear color, and lack of long, dense hair on their feet (Chapman \& Litvaitis, 2003; USFWS, 1998). The rabbit breeds between January and May and the gestation period lasts approximately 27 days (Chapman \& Litvaitis, 2003; Orr, 1940; USFWS, 1998). Within this time period, the rabbits can produce up to six litters with an average of two newborns per litter. In general, Sylvilagus spp. newborns are covered with fine hair, have their eyes closed, and have the ability to crawl at birth (Chapman \& Litvaitis, 2003; Orr, 1940). Adult rabbits live, on average, two to three years.

Sylvilagus spp. are generally closely tied to vegetative structure and species, thus making them sensitive to habitat alterations. More specifically, the riparian brush rabbit prefers habitat that consists of dense, shrub vegetation used for cover to avoid predation (Chapman \& Litvaitis, 2003; Orr, 1940). Rabbits build "forms," similar to nests, in the brush thickets when they tend to their young (Orr, 1940). These forms are small, approximately the size of the rabbit, and are bedded with foliage and fur. This is where the rabbits tend to their young. Seventy years ago, Orr (1940) observed up to 10 forms in an area approximately $13.5 \mathrm{~m} \times 7.3 \mathrm{~m}$ with tunnels connecting the forms to each other within the brush. These tunnels were round and maintained by the rabbits by biting the ends of the vegetation. The vegetation near the tunnel entrance was excluded from these 
activities, apparently to provide a visual barrier from would-be predators. In one study, predation, by both raptors and mammals, was found to be the primary known cause of death in translocated rabbits (Hamilton et al., 2010) and, according to Orr (1940), the threat of predation often determines rabbit behavior. For example, the reason that they are so closely associated with shrubbery is likely to avoid predation; and when they do venture from cover, they do so cautiously, one meter at a time. In fact, the maximum distance Orr (1940) observed a rabbit from the brush was less than 13 meters. In the open, the rabbit uses its powerful hearing, as well as other species alarm calls, to detect potential danger. Once alerted, the rabbits dart back into the brush and wait approximately six minutes until creeping back along the edges of the brush (Orr, 1940). These observations are consistent with observations at Caswell Memorial State Park (the Park) by USFWS (1998) who found rabbits in close proximity to brush, venturing no more than one meter from cover. The rabbit is most active during dawn and dusk; in the early mornings the rabbits can be seen basking in the sun. In general, foraging occurs in the morning and evening hours. Orr (1940) reported that weather played a role in the rabbit's foraging behavior. For instance, if there was a heavy fog the rabbits waited until it lifted before exposing themselves to danger. Likewise, a full moon would allow them to forage later into the evening. The species consumes mostly herbaceous materials in the spring and summer months. In the fall and winter months, their diet shifts to woody vegetation due to the lack of herbaceous material (Chapman \& Litvaitis, 2003). Orr (1940) reported that the brush rabbit prefer tips of vegetation, often standing on its two 
hind legs to reach. They also dig up plant roots for food, especially poison hemlock (Conium maculatum).

Williams and Basey (1986) conducted a riparian brush rabbit study along the San Joaquin, Tuolome, and Stanislaus Rivers within the rabbit's historical range. They measured and analyzed sites occupied by the riparian brush rabbit and desert cottontail (Sylvilagus audubonii), as well as unoccupied sites. All riparian brush rabbit occupied sites were within the Park. Although no statistical correlations were detected between habitat and rabbit presence, the authors did report some differences between occupied and unoccupied sites. For instance, the rabbits prefered sites with a more diverse understory--consisting of roughly equal cover of California rose (Rosa californica), blackberry (Ribes ursinus), coyote brush (Baccharis douglasii), and wild grape-compared to sites predominately composed of blackberry. The rabbit was not found in areas with willows (Salix spp.) and low leaf litter, which is associated with frequent flood events. Further, areas occupied by riparian brush rabbits had open canopies of valley oak (Quercus lobata) and box elder (Acer negundo). The rabbit may avoid dense-canopied areas since avian predators often hunt from perches in trees and have been found to be a major cause of rabbit mortality (Hamilton et al., 2010). The relevance of canopy closure needs to be studied further especially since it could have a direct effect on management decisions for rabbit habitat.

USFWS (1998) cites herbaceous materials as the most important food source for the rabbit and notes the significant role of shrubs used for cover. Basey (1990) observed the rabbit foraging on wild rose, blackberry, and exotic grasses. Further, rabbits prefer 
the brush densities that accompany valley oak savannas. In general, the rabbits will use tunnels within the brush to disperse.

Researchers believe the rabbit once occupied the riparian vegetation corridor adjacent to the Stanislaus, Tuolumne, and San Joaquin rivers in the Central Valley

(Williams \& Basey, 1986) and are now reduced to two naturally occurring populations, at the Park and Paradise Cut, and one introduced population at the Refuge. The Park is the largest area (104.4 ha) of intact habitat within the riparian brush rabbit's historic range (Larsen, 1993); all three locations are in San Joaquin County.

\section{Caswell Memorial State Park}

The Park is approximately 104.4 ha of valley oak riparian forest and is adjacent to the Stanislaus River southwest of Ripon, CA. The Park has a campground, a picnic area and approximately $6.4 \mathrm{~km}$ of hiking trails. Peak visitation is during the weekends in the summer season. Often, all 64 campsites are occupied and the picnic area parking lot is near capacity during summer. Visitation during summer weekdays is fairly low, averaging around 8-10 visitors per/day (personal observation). During the winter, the park is at its quietest with only 2-4 visitors per day, on average. Regardless of the season, most of the human activity is concentrated in the campground and picnic areas (Figure 2). 


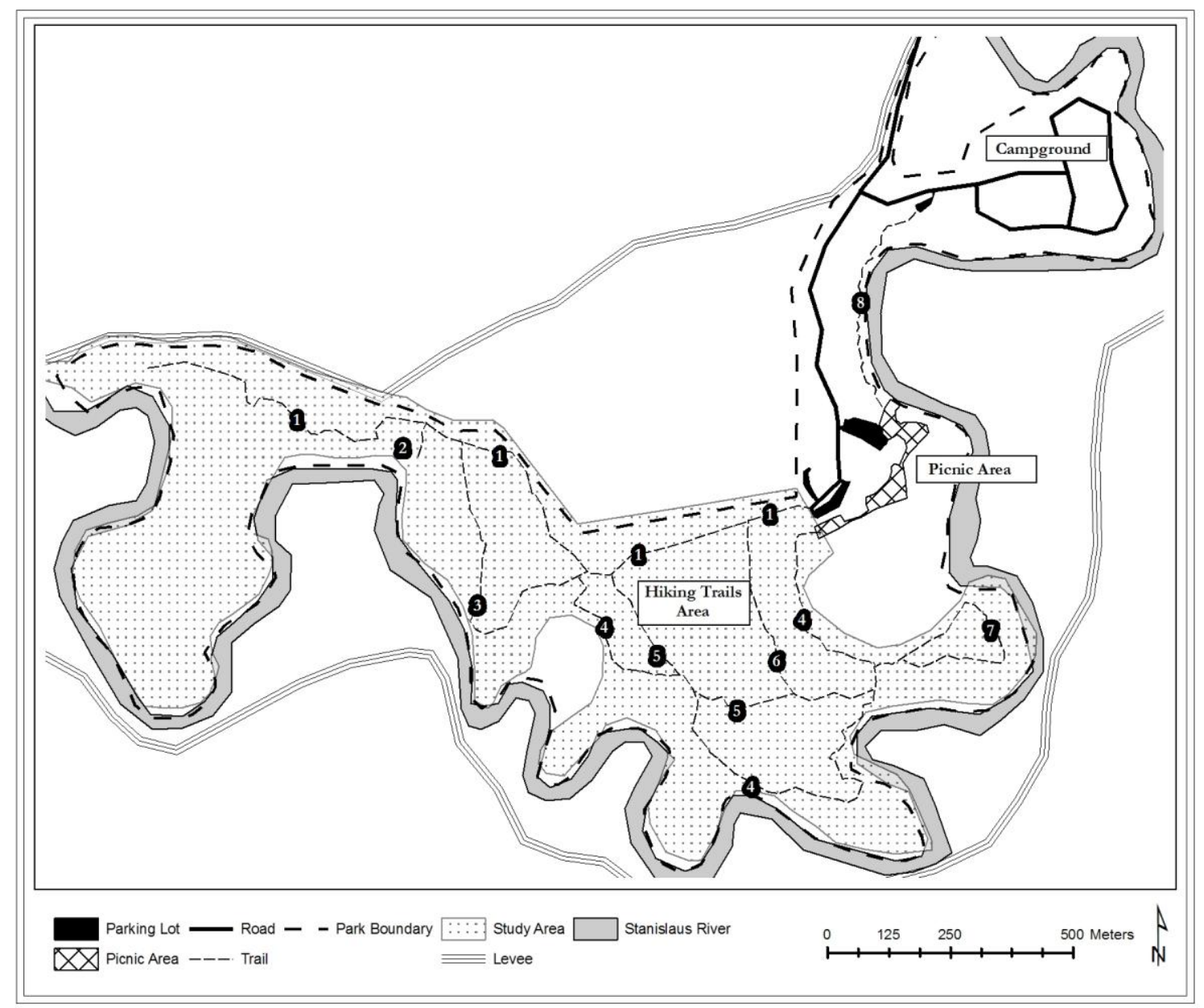

Figure 2. Study Site: Caswell Memorial State Park. This map shows the different uses of the park. The trail names are Fenceline (1), Rabbit's Run (2), Hidden Lake (3), Riverbend (4), Majestic Oaks (5), Gray Fox (6), Crows Loop (7), and Group Camp (8). Note. ArcMap 9.3 software was used to generate this map.

Prior to human settlement, valley oak riparian forests were widespread along the banks of the rivers in the Central Valley and were as wide as $16 \mathrm{~km}$ in some areas (Schoenherr, 1992). In the early $20^{\text {th }}$ century, a majority of these habitats were converted for agricultural use. During this time, the land, which is now designated as the Park, was used for hunting and trapping and was far less disturbed than the surrounding agricultural areas. In 1950, the Caswell family donated 54 ha to the State of California's Department 
of Parks and Recreation. An additional 50 ha was purchased around the same time and the Park was opened to the public in 1958 (California State Parks, 2010).

The Park gained wildlife researchers' attention after Williams and Kilburn's (1984) assessment of the State's riparian ecosystems identified the riparian brush rabbit population as one of the most vulnerable and with a high risk of extinction. In their analysis, Williams and Kilburn (1984) rated mammal species on their risk of extinction using the criteria identified in the Federal Endangered Species Act. They concluded 21 species were at risk of extirpation in the State and identified the rabbit as one of nine species in need of the highest level of protection. Habitat fragmentation and loss were deemed the leading causes for the population declines. The importance of the Park to the rabbit's survival was further elevated when Williams and Basey (1986) set out to inventory all riparian brush rabbit populations within their historical range and were only able to confirm the presence of the rabbit within the Park. Since it had been 40 years since the last recorded observation of the rabbit outside of the Park (Orr, 1940), it was assumed that the Park was the sole remaining location of this species, a belief that would persist until an additional population was discovered on private property in the late 1990s along the San Joaquin River (Williams et al., 2008).

Records indicate the rabbit population within the Park fluctuated greatly over the past several decades and periods of decline typically followed flood events. In 1976, the population was reported to be less than 20 individuals (Larsen, 1993) following that year's flood event where park staff in boats reportedly rescued rabbits that had climbed into trees (Basey, 1990; USFWS, 1998). In the winter of 1985-1986, Williams (1986) 
estimated that only 10 or fewer individuals remained after that winter's severe flooding event. Population numbers began to rebound with estimates of 88-452 rabbits in 1988, 320-540 in 1989 (Basey, 1990), and 170-608 (95\% confidence interval) in 1993 (Williams, 1993). Williams (1993) speculated that the 1993 population had neared the carrying capacity of the Park.

During his research, Basey (1990) reported that the highest concentrations of rabbits were in the campground, the picnic area, and Hidden Lake/Riverbend junction (Figure 2) based on his systematic observations of individual rabbits and their scat throughout the Park. Williams (1993) captured 41 rabbits with high concentrations along the western end of the Fenceline trail $(n=20)$ and in the campground area $(n=17)$ (Figure 2). Basey (1990) reported the density of rabbits to be 1.5-3.0 rabbits/ha while Williams (1993) reported the density to be 3.0 rabbits/ha $(\mathrm{SD}=1.13 ; 95 \%$ confidence interval=2.1 to 7.5 rabbits/ha).

In 1997, high waters returned and inundated $85 \%$ of the Park for approximately two weeks (San Joaquin County Multi-Species Habitat Conservation and Open Space Plan, 2000). Live trapping efforts immediately following this flood event did not result in any captures (USFWS, 1998).

Annual live-trapping surveys were conducted from 1998-2008 by the Endangered Species Recovery Group (M. R. Lloyd, personal communication, September 16, 2010) and focused along the Fenceline and Crow's Loop trails and in the campground (Table 1). The results of those efforts showed captures peaked in the winter of $2004(n=19)$ while the least number of individuals captured was in $2007(\mathrm{n}=1)$. 
I visited the Park on a weekly basis from 2000-2008. From 2000-2006, I observed, anecdotally, a gradual increase in rabbit activity, park-wide. Activity peaked in 2004 and 2005, when rabbits were seen foraging or darting for cover regularly in at least four discrete locations. Unlike Basey (1990) who reported very low activity along the Fenceline trailhead, I observed at least 4-7 rabbits during each morning visit, the highest level within the Park. Activity levels were also high at the Hidden Lake/Fenceline trail junction, along the Crow's Loop trail, and in the shrubs along the day use road across from the largest parking lot.

In each of these areas, I observed 2-4 rabbits per morning visit. Observable rabbit activity in the campground area was extremely low during the entire eight year period. I only saw two rabbits in this area, one in the summer of 2005 and one in the spring of 2006. This is interesting since Basey (1990) identified this area as having a high occurrence of rabbits and Williams (1993) reported trapping several individuals ( $\mathrm{n}=17)$ during his 1993 survey. 
Table 1. Summary of Live-Trapping Surveys, 1998-2008.

\begin{tabular}{|cccccc|}
\hline Year & Fenceline & Crow's Loop & Campground & Other & Total \\
\hline 1998 & 1 & 5 & - & - & 6 \\
1999 & 1 & 1 & - & - & 2 \\
2000 & 5 & - & - & - & 5 \\
2001 & - & 2 & - & - & 2 \\
2002 & 5 & 11 & - & - & 16 \\
2003 & 4 & 11 & - & 1 & 16 \\
2004 & 4 & 5 & - & 10 & 19 \\
2005 & - & - & - & 6 & 6 \\
2006 & 9 & - & - & - & 9 \\
2007 & 1 & - & - & - & 1 \\
2008 & 2 & - & - & - & 2 \\
\hline
\end{tabular}

Source: M. R. Lloyd, personal communication, September 18, 2010

In the winter/spring of 2004-05 and winter/spring of 2005-06, Modesto exceeded the mean annual rainfall $(31.6 \mathrm{~cm})$ and experienced $38.6 \mathrm{~cm}$ and $34.52 \mathrm{~cm}$ of precipitation, respectively (National Oceanic Atmospheric Administration (NOAA), 2006). As a result, in the spring of 2006 , flood waters once again covered portions (approximately 40\%) of the Park (personal observation). After the waters receded, weekly visits to the rabbit activity "hot spots" were quiet and no activity was observed over the next 22 months. This observation was corroborated by the annual live-trapping effort: very few rabbits, one in 2007 and two in 2008, were captured during this time period. Since 2008, park staff reported only a one rabbit observed (J. J. Ramsour, personal communication, July 25, 2010).

A review of aerial photography of the Park reveals a few subtle changes from 1957 (Figure 3) to 2009 (Figure 4). In 1957, the Park, while still densely canopied in areas, had more open, tree-free areas and the levee system was vegetated. By this time, 


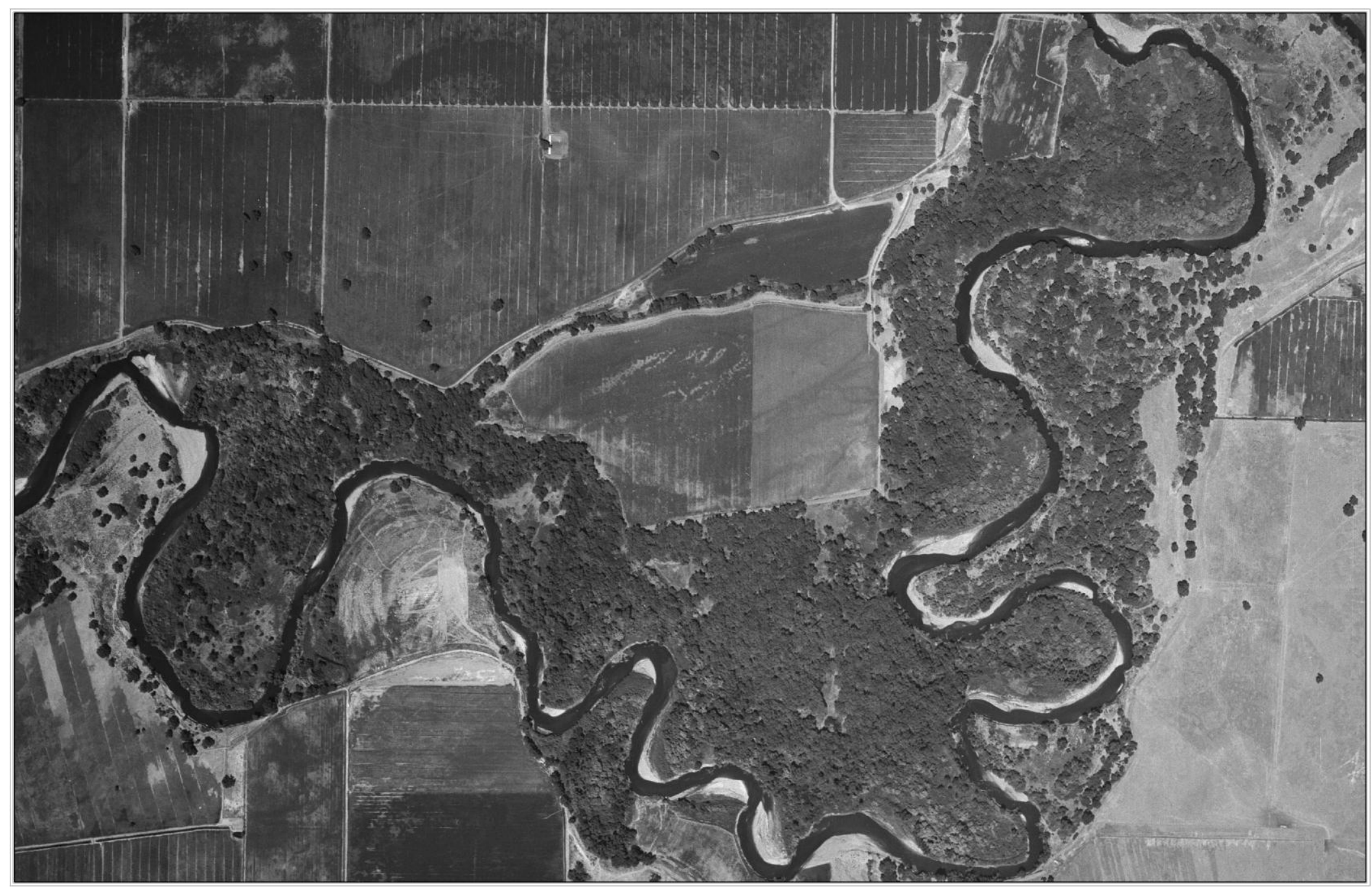

Figure 3. 1957 Aerial Photograph of Caswell Memorial State Park. Note. ArcMap 9.3 software was used to generate this map. 


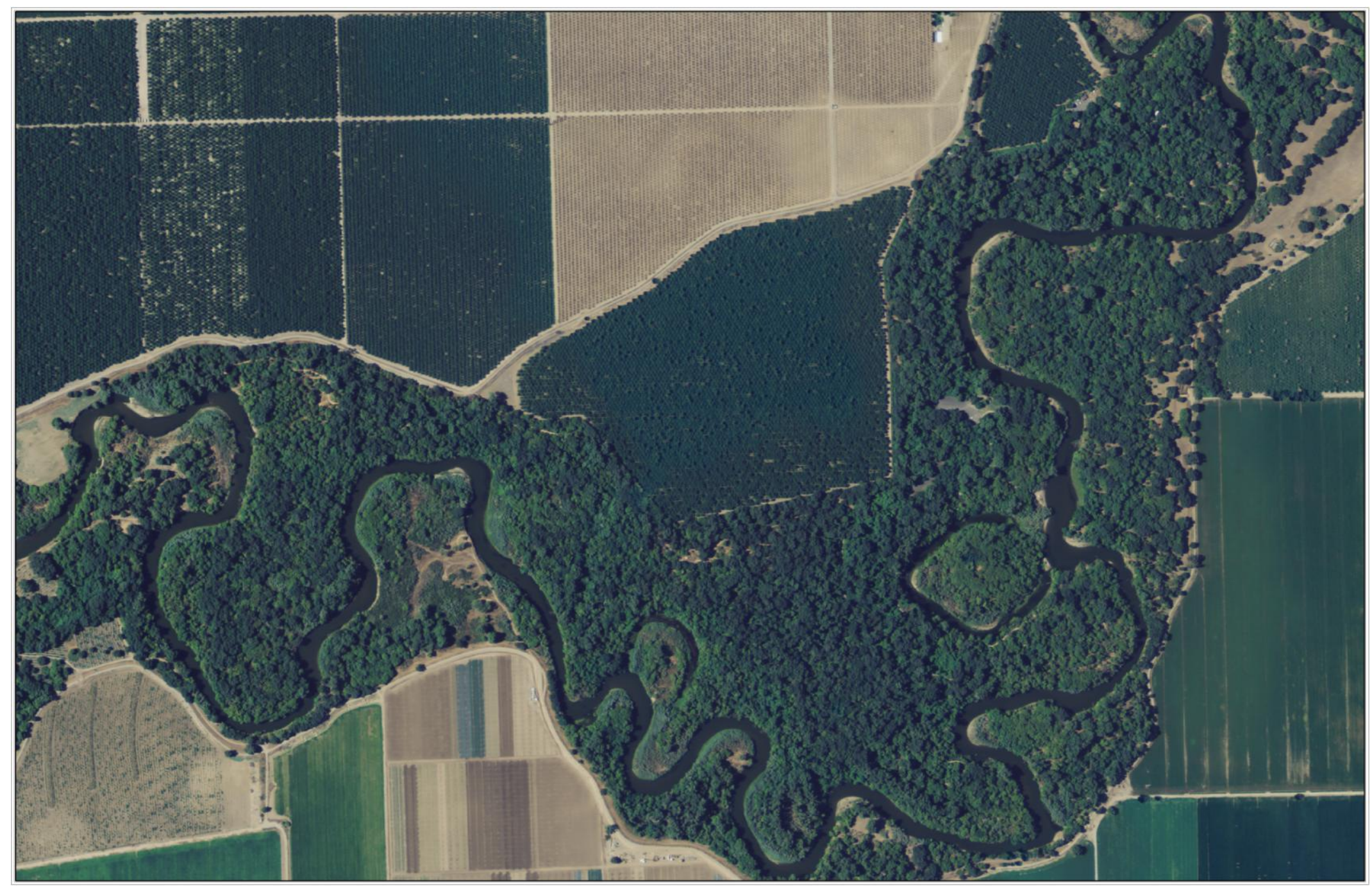

Figure 4. 2009 Aerial Photograph of Caswell Memorial State Park. Note. ArcMap 9.3 software was used to generate this map. 
the surrounding lands had already been largely converted to agriculture production. The 2009 photograph (Figure 4) shows a succession of canopy closure with few open areas and a vegetation free levee system.

\section{Research needs.}

Riparian brush rabbit. The conservation strategies outlined in the Recovery Plan for Upland Species of the San Joaquin Valley, California (USFWS, 1998) call for further investigation of riparian brush rabbit habitat needs and the acquisition of adjacent lands to existing habitat. Chapman and Litvaitis (2003) state that rabbit management should focus on understanding complex habitat relationships, in particular, vegetative structure. Until recently, Caswell Memorial State Park (“the Park") was considered the last known location of the rabbit. It still remains the largest riparian fragment within the historic range of the rabbit. The goal of this thesis research is to provide a characterization of the Park's habitat, information that does not currently exist and is needed to help guide restoration and habitat enhancement projects aimed at increasing the rabbit population. This research comes at a critical time since the restoration of acquired farm land is already underway at the San Joaquin River National Wildlife Refuge and additional acquisitions may follow in the coming years (Rentner \& Lloyd, 2010). Also, the habitat within the Park is not static, but continues to age and change. Williams (1993) speculated that the Park had reached the carrying capacity for the rabbit in 1993 ( $n=241 ; 95 \%$ confidence interval 170-608) which suggests habitat conditions were extremely favorable, if not optimal. Since the Park is the largest 
remaining natural habitat of the rabbit, it is critical that we describe habitat conditions soon before successional changes take place.

\section{Track plates and motion sensor cameras-data collection methods. In}

small mammal research, a variety of methods are used to detect species presence. The most common methods include observations, live traps, track plates, and motion-sensored cameras. Each method has its advantages and disadvantages. For example, live traps are most effective in identifying species and individual members of the population, an obvious advantage. On the other hand, traps can be disruptive to an animal's daily activities and lead to stress. Consequently, researchers constantly have to balance the effectiveness, cost, and practicality of each data collection method and choose the one that best fits their goals. This research will evaluate two of the most common methods used today, track plates and motion detection cameras. The goal will be to determine if either of these methods is more effective at detecting small mammals within a riparian forest, as well as comparing each methods cost and practicality.

Track plates have increased in popularity over the past few decades and are now one of the most common data collections methods used in mammal research. Track plates can be made from a range of materials, but most commonly aluminum is used since it is rigid, lightweight, and easily transported. The dimensions of the track plate vary depending on the target species and habitat. In most cases, a track plate is rectangular with a width between $20-60 \mathrm{~cm}$ and a length between $22-100 \mathrm{~cm}$. Once the track plates have been cut to size, they are placed on the ground and covered in an impressionable substrate, most often soot. Some researchers use an alternative mixture. I 
adopted a mixture of graphite, oil, and denaturalized alcohol due to its ease of application (Conners et al., 2004). The duration of sampling is also highly variable among studies. The track plates are commonly left in the field for a matter of days and checked and replaced every 24-48 hrs (Connors et al., 2004; Glennon, Porter, Demers, \& Kie, 2002; Hilty \& Merenlender, 2000; Ng, Dole, Sauvaiot, Riley, \& Valone, 2004; Winter, Johnson, \& Faaborg, 2000). Some samples will last weeks and are checked less frequently (Clevenger, Chruszcz, \& Gunson, 2001; Hackett et al., 2007; Hamm, Diller, Klug, \& McDonald, 2003; Meckstroth \& Miles, 2005). Baits are almost always used to increase mammal visits to the track plates.

Motion cameras are also growing in popularity and are increasingly used in mammal surveys. There are a wide range of models and prices. The first cameras used for habitat monitoring were $35 \mathrm{~mm}$ but now most models used are digital. Prices can range from below $\$ 100$ up to $\$ 700$. Most models share some basic features including short-term video, rapid photography, time, date and temperature stamp on each photo, and adjustable resolution. In general, the less expensive models will have fewer mega pixels, use motion to trip the cameras, and have fewer user options. The more expensive models use infrared technology to trigger the cameras, have quicker response times, and higher quality pictures. Performance varies among models (Culter \& Swann, 1999).

Cameras and track plates both measure a mammal's presence but not abundance. When using cameras, researchers first must run a series of tests to determine the optimal height and angle in regards to their target species. The camera is secured to a post or tree and often is aimed at a container of bait (Gompper et al., 2006; Hackett et al., 2007; Ng et 
al., 2004). Once set, the camera captures images from movement. The researcher will then collect the data a few days (Ng et al., 2004) to a few weeks later (Hackett et al., 2007). The images allow for a quick and easy identification process and also give data on time of activity. The biggest negative to cameras is their cost. They are several times the expense of track plates and, in areas with high human activity, the costly cameras are more likely to be stolen or vandalized, depleting the budget of the researcher as well as data.

While cameras and track plates provide similar data, their differences are such that knowing their effectiveness can save researchers time and money. So the question remains, is one method more effective than the other at detecting mammal presence? A few studies have attempted to answer this question. Gompper et al. (2006) evaluated several data collection techniques and compared infrared cameras to enclosed sootcovered track plates, and found their effectiveness depended on the size of the target species. For instance, cameras were more accurate detecting midsize and larger species, e.g. raccoon (Procyon lotor) and bear. On the other hand, track plates were more effective at detecting small carnivores. Hackett et al. (2007) also tested the effectiveness of the two methods on the eastern spotted skunk (Spilogale putorius) and found enclosed track plates to be the superior data collection method. His conclusion was based on two measurements: the period for initial contact with the plates was shorter by two days and animals visited the plates at a higher frequency.

Hilty and Merenlender (2000) also tested the two methods in an agricultural, oak woodland habitat matrix. They gave evidence that cameras, unlike track plates, were able 
to capture more species presence, specifically coyote and bobcat. Furthermore, when comparing the species composition from the two methods, they determined the track plates had a greater rate of false-negatives and would have portrayed an inaccurate list of species. They also believe cameras are better able to detect passive presence. In other words, target species do not need to be lured in by bait but rather the cameras can be set up along a trail and still capture the animal. Conversely, track plates consist of a foreign substance, e.g. soot, and the animal needs to be attracted by bait in order to leave an imprint. This requires the researcher to make more frequent trips to the data collection site resulting in increase in both labor cost and potential animal avoidance. Hilty and Merenlender (2000) also tested the need for bait at camera stations and their results indicated no difference between the baited and non-baited stations. This thesis study builds on these findings, and tests the two methods in a riparian forest habitat. Wildlife managers, more specifically rabbit managers, can incorporate this information into monitoring protocols, saving valuable time and capital.

Research objectives. The main objectives of this study were to characterize the habitat at the Caswell Memorial State Park (the Park) and to determine habitat preferences of the riparian brush rabbit (the rabbit) based on activity within various habitat structures and vegetation communities. This study investigated five specific research questions:

RQ 1. What are the key vegetation structures and the defining attributes and dominant plant species within each structure at Caswell Memorial State Park?

RQ 2. What animal species are present in the Park? 
RQ 3. What are the dominant habitat characteristics where the riparian brush rabbit is found?

RQ 4. Are cameras more effective than track plates at detecting small mammal presence, especially riparian brush rabbits?

RQ 5. What measures can be taken by managers to preserve and enhance the rabbit population at the Park? 


\section{Methods}

\section{Study Site}

This research focused on the riparian brush rabbit population at the Caswell Memorial State Park, which is the most intact and pristine riparian forest fragment in the rabbit historic range (USFWS, 1998). The Park is 104.4 ha in size and is located along the Stanislaus River, approximately $6 \mathrm{~km} \mathrm{SW}$ of Ripon, CA (Figure 1). Agricultural fields, consisting of mostly walnut orchards and grape vineyards, surround the Park, while urban development encroaches from the northeast. The most prevalent tree species within the Park is the box elder, while the dominant canopy trees are the valley oak, Fremont cottonwood (Populus fremontii), black walnut (Juglans californica), and Oregon ash (Fraxinus oregona). Willows (Salix spp.) are also present in the canopy but are limited in their distribution. The vegetative understory largely consists of California rose, golden current (Ribes aureum), blackberry (Rubus ursinus), coyote bush and sedge (Carex spp.) (USFWS, 1998). Throughout the Park, the canopy is generally dense, with few open sunny areas. The shrub species are scattered forming patch thickets below the canopy resulting in heterogeneous vegetative communities. It is believed that the rabbit occupies these shrub thickets (USFWS, 1998) in order to avoid predation (Chapman \& Litvaitis, 2003; USFWS, 1998). When seen, the rabbits are often foraging on exotic grasses not far from the brush thickets (Orr, 1940; USFWS, 1998).

Several other mammalian species inhabit riparian forests. Based on their diets, these species can be classified into four groups. The herbivores, includes mouse spp., the native riparian woodrat (Neotoma fuscipes riparia), riparian brush rabbit, and western 
gray squirrel (Sciurus griseus). The next level, omnivores, include the black rat (Rattus rattus), striped skunk (Mephitis mephitis), feral cat (Felis sylvestris), Virginia opossum (Didelphis virginiana), and raccoon (Procyon lotor). The secondary predators, or mesopredators, consist of the gray fox (Urocyon cinereoargenteus), the red fox (Vulpes vulpes), and bobcat (Lynx rufus). The top predator is the coyote (Canus latrans).

\section{Field Methods}

Within the Park's trails area (Figure 2), I qualitatively described the dominant habitat structures based on the presence of four common vegetation layers (Table 2). For each habitat structure defined, I choose a stratified random sample of 24-26 sample sites. These sample sites were selected using four major transects within the trails area of the Park using a random numbers table to determine transect selection, distance traveled along the selected transect, and distance traveled from the transect.

Each sample site was at least $100 \mathrm{~m}^{2}$ (Bonham, 1989). In order to measure plant species at the ground level, I established two 10m-transects within each sample site. Along these transects, I recorded the plant species at $10 \mathrm{~cm}$ intervals, providing data on composition and cover, allowing description of each sample site individually and composition by plant species for each habitat structure.

\section{Table 2. Definitions of Vegetation Layers.}

\begin{tabular}{|ccccc|}
\hline Vegetation Layer & Herbaceous & Shrubs & Secondary Canopy & High Canopy \\
Vegetation Height $(\mathbf{m})$ & $<1$ & $<3$ but $>1$ & $>3$ but $<20$ & $>20$ \\
\hline
\end{tabular}

I also measured rabbit presence, and other mammal presence, using infrared cameras (Model: I450, Stealth Cam LLC) (Diaz, Torre, Peris, Tena, 2005) and baited aluminum track plates (28 x $43 \mathrm{~cm})$ (Clevenger et al., 2001; Conners et al., 2005; Hamm 
et al., 2003; Winter, Johnson, \& Faaborg, 2000). The location of the cameras and track plates within each sample site was determined by using a random number table (Hamm et al., 2003; Winter et al., 2000). Each sample site $(\mathrm{n}=125)$ was sampled once with cameras for a four-day period between July and October, 2007. Two stakes were driven in the ground and the camera was mounted approximately $60 \mathrm{~cm}$ above the ground and positioned at approximately 80 degrees. In addition to the cameras, a subset of the sample sites $(n=60)$ was sampled for a four-day period using track plates. The track plates were covered with a mixture of graphite, denatured ethyl alcohol and mineral oil (Conners et al., 2005). The sample sites were baited once with a mixture of oats, apples, and molasses.

\section{Analysis}

I used Geographical Information Systems (GIS) to describe the data's spatial relationships and to illustrate management recommendations. I used General Linear Models (SPSS 14) to detect statistically significant differences between sites and to determine if relationships existed between plant and animal species. I used chi-square analysis (SPSS 14) to determine if differences exist between cameras and track plates. Results were determined to be statistically significant if the p-value was 0.05 or less. 


\section{Results}

\section{RQ1 \& RQ2: Habitat Structure, Plant, and Animal Species}

Based on habitat sampling, I identified five habitat structure classes within the

Park using the presence or absence of the various vegetation layers (Table 3). Within each of the five habitat classes, I selected 24-26 sample sites for a total of 125 sites.

Twenty-four vegetation species were identified (Table 4), of which, nine were tree species, five were shrubs, and 10 were herbaceous species. Throughout the Park, Pacific blackberry was the most common plant species at the $1 \mathrm{~m}$ level and was found at 89 of 125 sites (71\%). Pacific blackberry was on average $83 \mathrm{~cm}(\mathrm{SD}=17.32)$ in height. Seven mammal species were recorded during the study with raccoon being the most common, occurring at 38 sites (Table 5).

Structure A sites included a high canopy, a secondary canopy, shrubs and herbaceous species (Table 2). These sites included 15 vegetation species. Common in the understory of this structure was Pacific blackberry, box elder, Santa Barbra sedge, and golden currant (Figure 5). Using the GLM to analyze the vegetation data between structures, I found that structure A had significantly higher cover of golden currant than structures $\mathrm{C}(\mathrm{F}(1,4)=4.229, \mathrm{p}=0.023)$ or $\mathrm{E}(\mathrm{F}(1,4)=4.229, \mathrm{p}=0.012)$. In addition, structure A had more cover of box elder than structure $B(F(1,4)=3.48, p=0.003)$ and lower cover of Santa Barbra sedge than structure $\mathrm{C}(\mathrm{F}(1,4)=3.48, \mathrm{p}=0.016)$. As for mammal species, I detected six of the seven species found in this study; the rabbit was absent. The most common mammals were the rat/mouse spp., which had the highest levels among all structures $(n=12)$. 
Table 3. Habitat Structures Defined by the Presence of Vegetation Layers.

\begin{tabular}{|lccccc|}
\hline \multirow{2}{*}{ Vegetation Layer } & \multicolumn{6}{c|}{ Habitat Structure } & E \\
\hline High Canopy & A & B & C & D & X \\
Secondary Canopy & X & X & X & & \\
Shrub & X & & & $X$ & $X$ \\
Herbaceous & X & X & & X & \\
\hline
\end{tabular}

Sites within structure B had a high canopy, shrubs, and herbaceous species. Eleven of the vegetation species were detected in this structure. Some of the more common species include Pacific blackberry, California rose, Santa Barbra sedge, and stinging nettle (Figure 6). There was a significantly higher level of cover of California rose when compared to structure $\mathrm{A}(\mathrm{F}(1,4)=14.00, \mathrm{p}=<0.00)$, structure $\mathrm{C}(\mathrm{F}(1,4)=14.00$, $\mathrm{p}=<0.00)$, structure $\mathrm{D}(\mathrm{F}(1,4)=14.00, \mathrm{p}=<0.00)$, and structure $\mathrm{E}(\mathrm{F}(1,4)=14.00, \mathrm{p}=$ <0.00). Also, this structure had significantly less cover of box elder than structure D $(\mathrm{F}(1,4)=3.992, \mathrm{p}=0.041)$ and less cover of Santa Barbra sedge than structure $\mathrm{C}$ $(\mathrm{F}(1,4)=3.48, \mathrm{p}=0.020)$. Similar to structure $\mathrm{A}$, six mammalian species were detected in structure B. The most common was rat/mouse spp. $(n=9)$, and the rabbit was absent.

Structure C sites included high canopy and herbaceous species. Eighteen vegetation species were found in this structure. The most frequent species sampled was Pacific blackberry, Santa Barbra sedge, box elder, and bedstraw (Figure 7). Structure C had a statistically significant lower cover of golden currant than structure A $(F(1,4)=4.229, p=0.023)$ and a lower cover of California rose than structure $B$ $(\mathrm{F}(1,4)=14.00, \mathrm{p}=<0.00)$ and more cover of Pacific blackberry than structure $\mathrm{E}$ 
$(\mathrm{F}(1,4)=5.487, \mathrm{p}=0.038)$. Six mammal species were detected in this structure; the rabbit was absent. The most common mammal was the raccoon $(n=6)$.

Structure D sites included a secondary canopy, with shrubs and herbaceous species. Fifteen vegetation species were detected in this structure. The most frequently detected species included Pacific blackberry, Santa Barbra sedge and stinging nettle (Figure 8). As stated above, when compared to structure B, structure D had less California rose cover $(\mathrm{F}(1,4)=14.00, \mathrm{p}=<0.00)$ and significantly greater box elder cover $(\mathrm{F}(1,4)=3.992, \mathrm{p}=0.041)$. All seven mammal species were recorded within this structure and rat/mouse spp. were the most common $(n=10)$. The rabbit was detected at three sites within this structure. 
Table 4. Plant Composition and Cover Across All Sites.

\begin{tabular}{|llcc|}
\hline Common Name & Scientific Name & Frequency & Cover \\
\hline Arrow Willow & Salix lasiolepis & 4 & 7 \\
Bedstraw & Galium aparine & 21 & 30 \\
Black Walnut & Juglans californica & 7 & 3 \\
Black Willow & Salix gooddingii & 2 & 2 \\
Box Elder & Acer negundo & 57 & 8 \\
Brome & Bromus sps. & 9 & 37 \\
Button Bush & Cephalanthus occidentalis & 1 & 5 \\
California Rose & Rosa californica & 44 & 16 \\
Coyote Bush & Baccharis pilularis & 2 & 35 \\
Cyperus & Cyperus sps & 1 & 1 \\
Elderberry & Sambucus mexicana & 16 & 7 \\
Fremont Cottonwood & Populus fremontii & 1 & 7 \\
Golden Currant & Ribes aureum & 34 & 30 \\
Italian Thistle & Carduus pycnocephalus & 2 & 3 \\
MugWart & Artemisia ludoviciana & 3 & 3 \\
Mustard & Brassica nigra & 1 & 4 \\
Night Shade & Solanum sarrachoides & 5 & 4 \\
Oregon Ash & Faxinus latifolia & 9 & 7 \\
Pacific Blackberry & Rubus ursinus & 89 & 56 \\
Parsley & Petroselinum sps. & 5 & 60 \\
Sandbar Willow & Salix exigua & 2 & 1 \\
Santa Barbra Sedge & Carex barbarae & 68 & 47 \\
Stinging Neetle & Urtica dioica & 35 & 22 \\
Valley Oak & Quercus lobata & 7 & 10 \\
Wild Grape & Vitis californica & 28 & 17 \\
Downwood & - & 80 & 6 \\
\hline
\end{tabular}

*Frequency is the number of sites in which species occurred.

**Cover is the average (\%) in sites where species occurred. 
Table 5. Plant Composition and Cover for Structure A.

\begin{tabular}{|llcc|}
\hline Common Name & Scientific Name & Frequency & Cover \\
\hline Arrow Willow & Salix lasiolepis & 2 & 8 \\
Bedstraw & Galium aparine & 0 & 0 \\
Black Walnut & Juglans californica & 0 & 0 \\
Black Willow & Salix gooddingii & 1 & 1 \\
Box Elder & Acer negundo & 15 & 11 \\
Brome & Bromus sps. & 1 & 2 \\
Button Bush & Cephalanthus occidentalis & 1 & 5 \\
California Rose & Rosa californica & 8 & 20 \\
Coyote Bush & Baccharis pilularis & 1 & 20 \\
Cyperus & Cyperus sps & 0 & 0 \\
Elderberry & Sambucus mexicana & 8 & 8 \\
Fremont Cottonwood & Populus fremontii & 0 & 0 \\
Golden Currant & Ribes aureum & 12 & 32 \\
Italian Thistle & Carduus pycnocephalus & 0 & 0 \\
MugWart & Artemisia ludoviciana & 0 & 0 \\
Mustard & Brassica nigra & 0 & 0 \\
Night Shade & Solanum sarrachoides & 1 & 2 \\
Oregon Ash & Faxinus latifolia & 1 & 7 \\
Pacific Blackberry & Rubus ursinus & 18 & 70 \\
Parsley & Petroselinum sps. & 0 & 0 \\
Sandbar Willow & Salix exigua & 0 & 0 \\
Santa Barbra Sedge & Carex barbarae & 12 & 26 \\
Stinging Neetle & Urtica dioica & 6 & 27 \\
Valley Oak & Quercus lobata & 1 & 5 \\
Wild Grape & Vitis californica & 6 & 5 \\
Downwood & - & 15 & 7 \\
\hline & & & \\
Frequency is the number & 12 & \\
\hline
\end{tabular}

*Frequency is the number of sites in which species occurred.

$* *$ Cover is the average $(\%)$ in sites where species occurred. 
Table 6. Plant Composition and Cover for Structure B.

\begin{tabular}{|c|c|c|c|}
\hline Common Name & Scientific Name & Frequency & Cover \\
\hline Arrow Willow & Salix lasiolepis & 0 & 0 \\
\hline Bedstraw & Galium aparine & 1 & 79 \\
\hline Black Walnut & Juglans californica & 0 & 0 \\
\hline Black Willow & Salix gooddingii & 0 & 0 \\
\hline Box Elder & Acer negundo & 1 & 8 \\
\hline Brome & Bromus sps. & 2 & 4 \\
\hline Button Bush & Cephalanthus occidentalis & 0 & 0 \\
\hline California Rose & Rosa californica & 20 & 23 \\
\hline Coyote Bush & Baccharis pilularis & 0 & 0 \\
\hline Cyperus & Cyperus sps & 0 & 0 \\
\hline Elderberry & Sambucus mexicana & 4 & 3 \\
\hline Fremont Cottonwood & Populus fremontii & 0 & 0 \\
\hline Golden Currant & Ribes aureum & 7 & 33 \\
\hline Italian Thistle & Carduus pycnocephalus & 0 & 0 \\
\hline MugWart & Artemisia ludoviciana & 0 & 0 \\
\hline Mustard & Brassica nigra & 0 & 0 \\
\hline Night Shade & Solanum sarrachoides & 1 & 3 \\
\hline Oregon Ash & Faxinus latifolia & 0 & 0 \\
\hline Pacific Blackberry & Rubus ursinus & 23 & 67 \\
\hline Parsley & Petroselinum sps. & 0 & 0 \\
\hline Sandbar Willow & Salix exigua & 0 & 0 \\
\hline Santa Barbra Sedge & Carex barbarae & 11 & 32 \\
\hline Stinging Neetle & Urtica dioica & 9 & 34 \\
\hline Valley Oak & Quercus lobata & 2 & 6 \\
\hline Wild Grape & Vitis californica & 11 & 32 \\
\hline Downwood & - & 13 & 4 \\
\hline
\end{tabular}

*Frequency is the number of sites in which species occurred.

**Cover is the average (\%) in sites where species occurred. 
Table 7. Plant Composition and Cover for Structure C.

\begin{tabular}{|llcc|}
\hline Common Name & Scientific Name & Frequency & Cover \\
\hline Arrow Willow & Salix lasiolepis & 0 & 0 \\
Bedstraw & Galium aparine & 9 & 32 \\
Black Walnut & Juglans californica & 4 & 2 \\
Black Willow & Salix gooddingii & 1 & 3 \\
Box Elder & Acer negundo & 11 & 6 \\
Brome & Bromus sps. & 1 & 31 \\
Button Bush & Cephalanthus occidentalis & 0 & 0 \\
California Rose & Rosa californica & 4 & 6 \\
Coyote Bush & Baccharis pilularis & 0 & 0 \\
Cyperus & Cyperus sps & 0 & 0 \\
Elderberry & Sambucus mexicana & 2 & 2 \\
Fremont Cottonwood & Populus fremontii & 1 & 7 \\
Golden Currant & Ribes aureum & 3 & 5 \\
Italian Thistle & Carduus pycnocephalus & 1 & 3 \\
MugWart & Artemisia ludoviciana & 0 & 0 \\
Mustard & Brassica nigra & 0 & 0 \\
Night Shade & Solanum sarrachoides & 2 & 6 \\
Oregon Ash & Faxinus latifolia & 1 & 1 \\
Pacific Blackberry & Rubus ursinus & 19 & 47 \\
Parsley & Petroselinum sps. & 1 & 75 \\
Sandbar Willow & Salix exigua & 1 & 2 \\
Santa Barbra Sedge & Carex barbarae & 18 & 68 \\
Stinging Neetle & Urtica dioica & 5 & 3 \\
Valley Oak & Quercus lobata & 3 & 19 \\
Wild Grape & Vitis californica & 3 & 4 \\
Downwood & - & 5 \\
\hline
\end{tabular}

*Frequency is the number of sites in which species occurred.

**Cover is the average (\%) in sites where species occurred. 
Table 8. Plant Composition and Cover for Structure D.

\begin{tabular}{|llcc|}
\hline Common Name & Scientific Name & Frequency & Cover \\
\hline Arrow Willow & Salix lasiolepis & 1 & 10 \\
Bedstraw & Galium aparine & 2 & 21 \\
Black Walnut & Juglans californica & 2 & 4 \\
Black Willow & Salix gooddingii & 1 & 1 \\
Box Elder & Acer negundo & 16 & 8 \\
Brome & Bromus sps. & 2 & 21 \\
Button Bush & Cephalanthus occidentalis & 0 & 0 \\
California Rose & Rosa californica & 6 & 6 \\
Coyote Bush & Baccharis pilularis & 1 & 50 \\
Cyperus & Cyperus sps & 0 & 0 \\
Elderberry & Sambucus mexicana & 1 & 23 \\
Fremont Cottonwood & Populus fremontii & 0 & 0 \\
Golden Currant & Ribes aureum & 10 & 37 \\
Italian Thistle & Carduus pycnocephalus & 0 & 0 \\
MugWart & Artemisia ludoviciana & 1 & 3 \\
Mustard & Brassica nigra & 0 & 0 \\
Night Shade & Solanum sarrachoides & 1 & 5 \\
Oregon Ash & Faxinus latifolia & 6 & 8 \\
Pacific Blackberry & Rubus ursinus & 17 & 54 \\
Parsley & Petroselinum sps. & 2 & 27 \\
Sandbar Willow & Salix exigua & 0 & 0 \\
Santa Barbra Sedge & Carex barbarae & 13 & 37 \\
Stinging Neetle & Urtica dioica & 10 & 28 \\
Valley Oak & Quercus lobata & 0 & 0 \\
Wild Grape & Vitis californica & 6 & 15 \\
Downwood & - & 7 & 7 \\
\hline Frequency & & & \\
\hline
\end{tabular}

*Frequency is the number of sites in which species occurred.

**Cover is the average (\%) in sites where species occurred. 
Table 9. Plant Composition and Cover for Structure E.

\begin{tabular}{|llcc|}
\hline Common Name & Scientific Name & Frequency & Cover \\
\hline Arrow Willow & Salix lasiolepis & 1 & 2 \\
Bedstraw & Galium aparine & 9 & 25 \\
Black Walnut & Juglans californica & 1 & 1 \\
Black Willow & Salix gooddingii & 0 & 0 \\
Box Elder & Acer negundo & 14 & 5 \\
Brome & Bromus sps. & 3 & 83 \\
Button Bush & Cephalanthus occidentalis & 0 & 0 \\
California Rose & Rosa californica & 6 & 4 \\
Coyote Bush & Baccharis pilularis & 0 & 0 \\
Cyperus & Cyperus sps & 1 & 1 \\
Elderberry & Sambucus mexicana & 1 & 2 \\
Fremont Cottonwood & Populus fremontii & 0 & 0 \\
Golden Currant & Ribes aureum & 2 & 5 \\
Italian Thistle & Carduus pycnocephalus & 1 & 2 \\
MugWart & Artemisia ludoviciana & 2 & 4 \\
Mustard & Brassica nigra & 1 & 4 \\
Night Shade & Solanum sarrachoides & 0 & 0 \\
Oregon Ash & Faxinus latifolia & 1 & 5 \\
Pacific Blackberry & Rubus ursinus & 12 & 31 \\
Parsley & Petroselinum sps. & 2 & 85 \\
Sandbar Willow & Salix exigua & 0 & 0 \\
Santa Barbra Sedge & Carex barbarae & 14 & 60 \\
Stinging Neetle & Urtica dioica & 5 & 4 \\
Valley Oak & Quercus lobata & 1 & 2 \\
Wild Grape & Vitis californica & 2 & 2 \\
Downwood & - & 5 & 5 \\
\hline
\end{tabular}

*Frequency is the number of sites in which species occurred.

$* *$ Cover is the average $(\%)$ in sites where species occurred. 
Table 10. Animal Species Presence by Habitat Structure.

\begin{tabular}{|ccccccc|}
\hline \multirow{2}{*}{ Mammal Species } & All & A & B & C & D & E \\
\hline Riparian Brush Rabbit & 4 & 0 & 0 & 0 & 3 & 1 \\
Gray Fox & 26 & 5 & 3 & 4 & 7 & 7 \\
Raccoon & 38 & 7 & 5 & 6 & 8 & 12 \\
Virginia Opossum & 18 & 2 & 1 & 3 & 6 & 6 \\
Gray Squirrel & 14 & 3 & 1 & 3 & 1 & 6 \\
Mouse/Rat sps. & 38 & 12 & 9 & 3 & 10 & 4 \\
\hline
\end{tabular}

Structure E included a secondary canopy and herbaceous species. Eighteen of the vegetation species were found within this structure. The most common species were Santa Barbra sedge, box elder, and Pacific blackberry (Figure 9). This structure had greater Pacific blackberry cover than structure A $(\mathrm{F}(1,4)=5.487, \mathrm{p}=0.021)$ and structure $\mathrm{B}$ $(\mathrm{F}(1,4)=5.487, \mathrm{p}=0.000)$ and less cover than structure $\mathrm{C}(\mathrm{F}(1,4)=5.487, \mathrm{p}=0.038)$. Also, this structure had significantly less cover of golden currant than structure A $(F(1,4)=4.229, p=0.012)$ and less cover of California rose than structure $B(F(1,4)=14.00$, $\mathrm{p}=<0.00$ ). All seven mammal species detected during the study were found in this structure. The most common mammal is the raccoon $(n=12)$ and the rabbit was found at one site. 
Table 11. Five Most Common Plant Species within Each Habitat Structure.

\begin{tabular}{|c|c|c|c|c|}
\hline Structure & $\begin{array}{c}\text { Species } \\
\end{array}$ & Frequency & \% Cover & Mean Height $(\mathrm{cm})$ \\
\hline \multirow{6}{*}{$\begin{array}{l}\text { All Sites } \\
(\mathrm{n}=125)\end{array}$} & Pacific Blackberry & 89 & 56 & 89 \\
\hline & Santa Barbra Sedge & 68 & 47 & 67 \\
\hline & Box Elder & 57 & 8 & 262 \\
\hline & California Rose & 44 & 16 & 155 \\
\hline & Stinging Neetle & 35 & 22 & 168 \\
\hline & All Vegetation & & 107 & 141 \\
\hline \multirow{6}{*}{$A(n=25)$} & Pacific Blackberry & 18 & 70 & 83 \\
\hline & Box Elder & 15 & 11 & 255 \\
\hline & Santa Barbra Sedge & 12 & 26 & 70 \\
\hline & Golden Currant & 12 & 32 & 143 \\
\hline & California Rose & 8 & 20 & 168 \\
\hline & All Vegetation & & 104 & 162 \\
\hline \multirow{6}{*}{$B(n=25)$} & Pacific Blackberry & 23 & 67 & 79 \\
\hline & California Rose & 20 & 23 & 168 \\
\hline & Santa Barbra Sedge & 11 & 32 & 78 \\
\hline & Vitis californica & 11 & 32 & 147 \\
\hline & Stinging Neetle & 9 & 34 & 178 \\
\hline & All Vegetation & & 137 & 137 \\
\hline \multirow{6}{*}{$C(n=24)$} & Pacific Blackberry & 19 & 47 & 101 \\
\hline & Santa Barbra Sedge & 18 & 68 & 67 \\
\hline & Box Elder & 11 & 6 & 272 \\
\hline & Bedstraw & 9 & 32 & 36 \\
\hline & Stinging Neetle & 5 & 3 & 130 \\
\hline & All Vegetation & & 114 & 119 \\
\hline \multirow{6}{*}{$D(n=26)$} & Pacific Blackberry & 17 & 54 & 79 \\
\hline & Box Elder & 16 & 8 & 210 \\
\hline & Santa Barbra Sedge & 13 & 37 & 78 \\
\hline & Stinging Neetle & 10 & 34 & 178 \\
\hline & Goden Currant & 10 & 37 & 216 \\
\hline & All Vegetation & & 100 & 163 \\
\hline \multirow{6}{*}{$E(n=25)$} & Santa Barbra Sedge & 14 & 60 & 78 \\
\hline & Box Elder & 14 & 5 & 210 \\
\hline & Pacific Blackberry & 12 & 31 & 79 \\
\hline & Bedstraw & 9 & 25 & 110 \\
\hline & California Rose & 6 & 23 & 168 \\
\hline & All Vegetation & & 80 & 119 \\
\hline
\end{tabular}




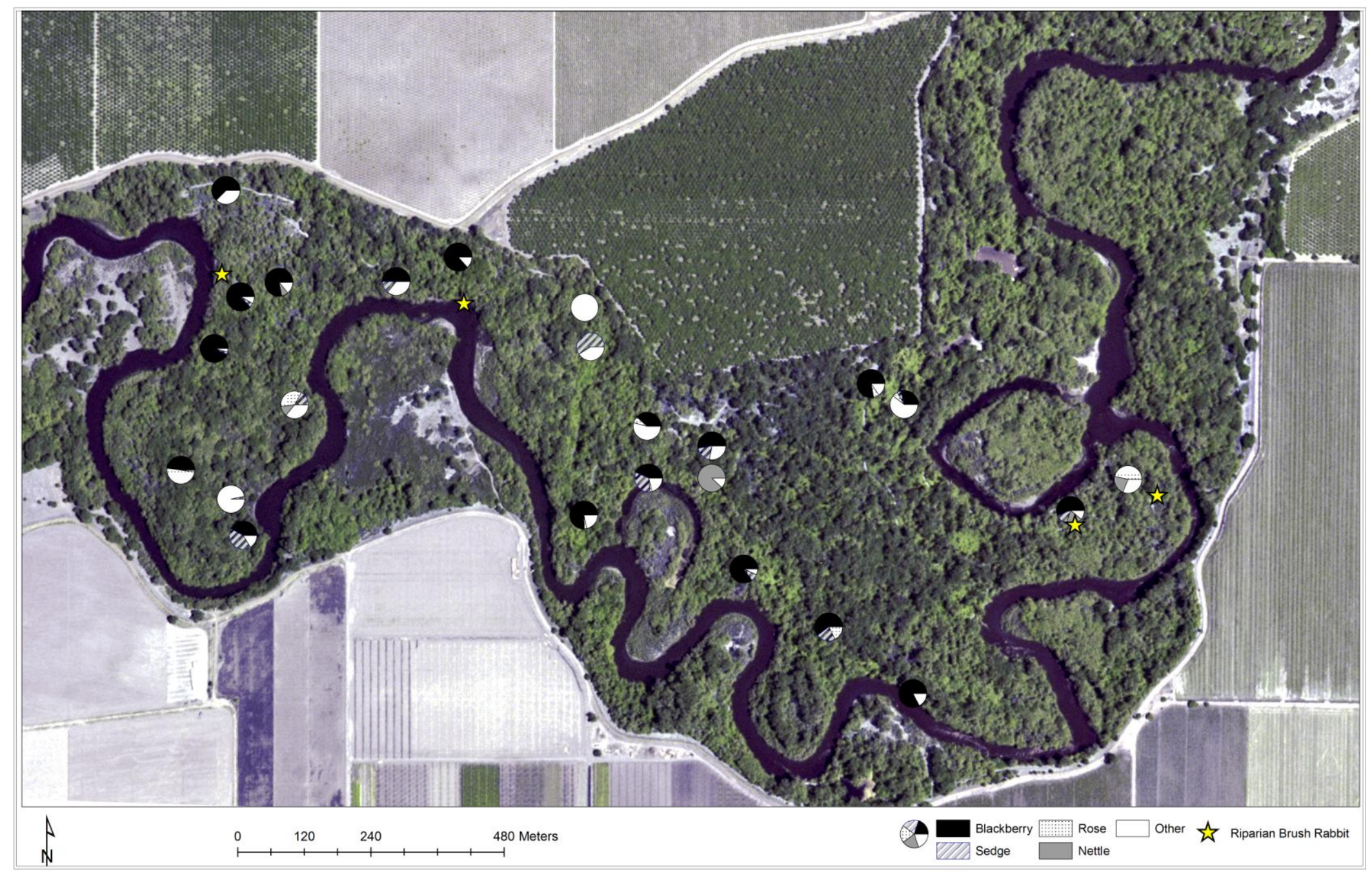

Figure 5. Map of Structure A Understory Plant Species Proportional Cover by Site. Note. ArcMap 9.3 software was used to generate this map. 


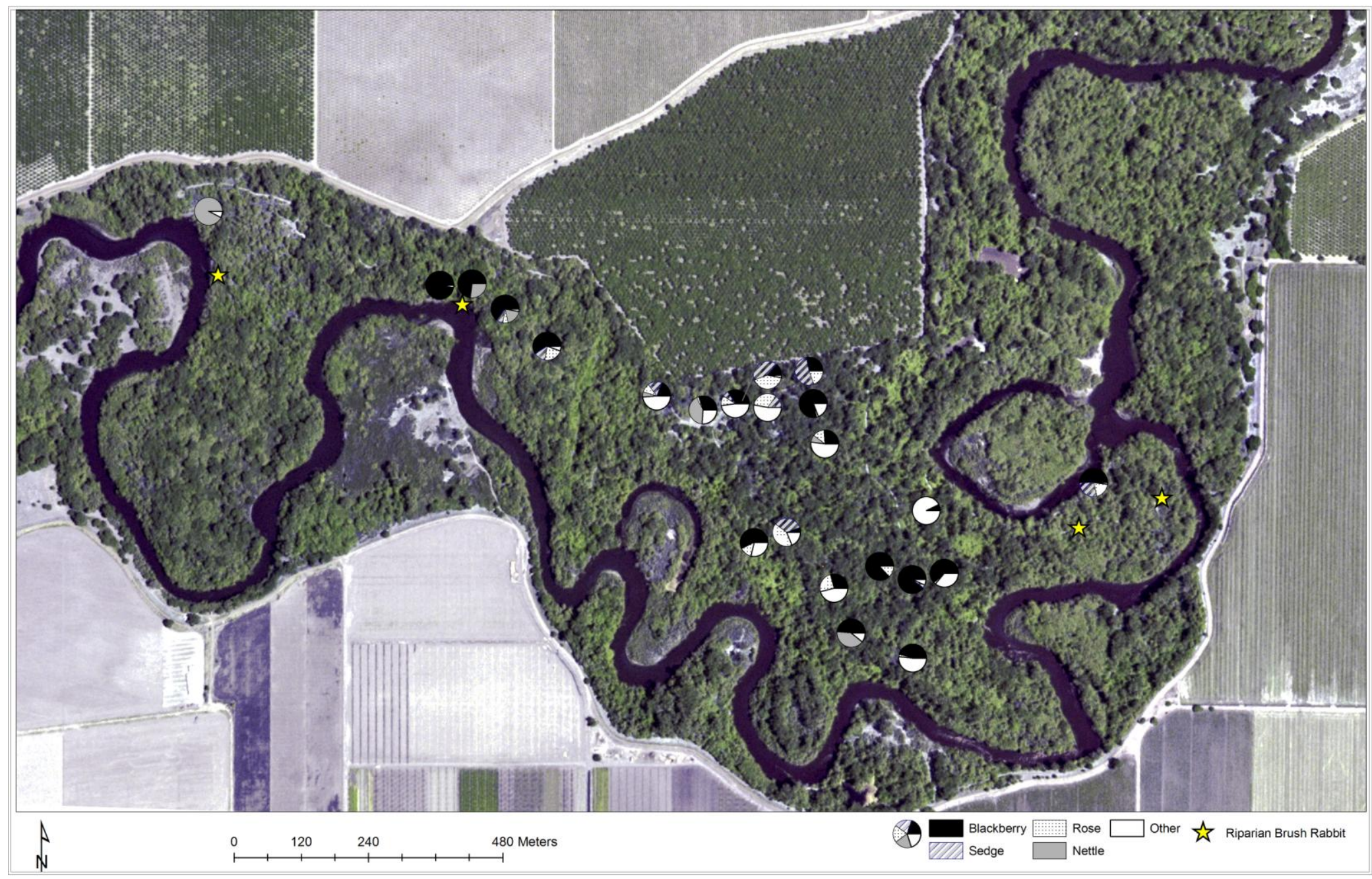

Figure 6. Map of Structure B Understory Plant Species Proportional Cover by Site. Note. ArcMap 9.3 software was used to generate this map. 


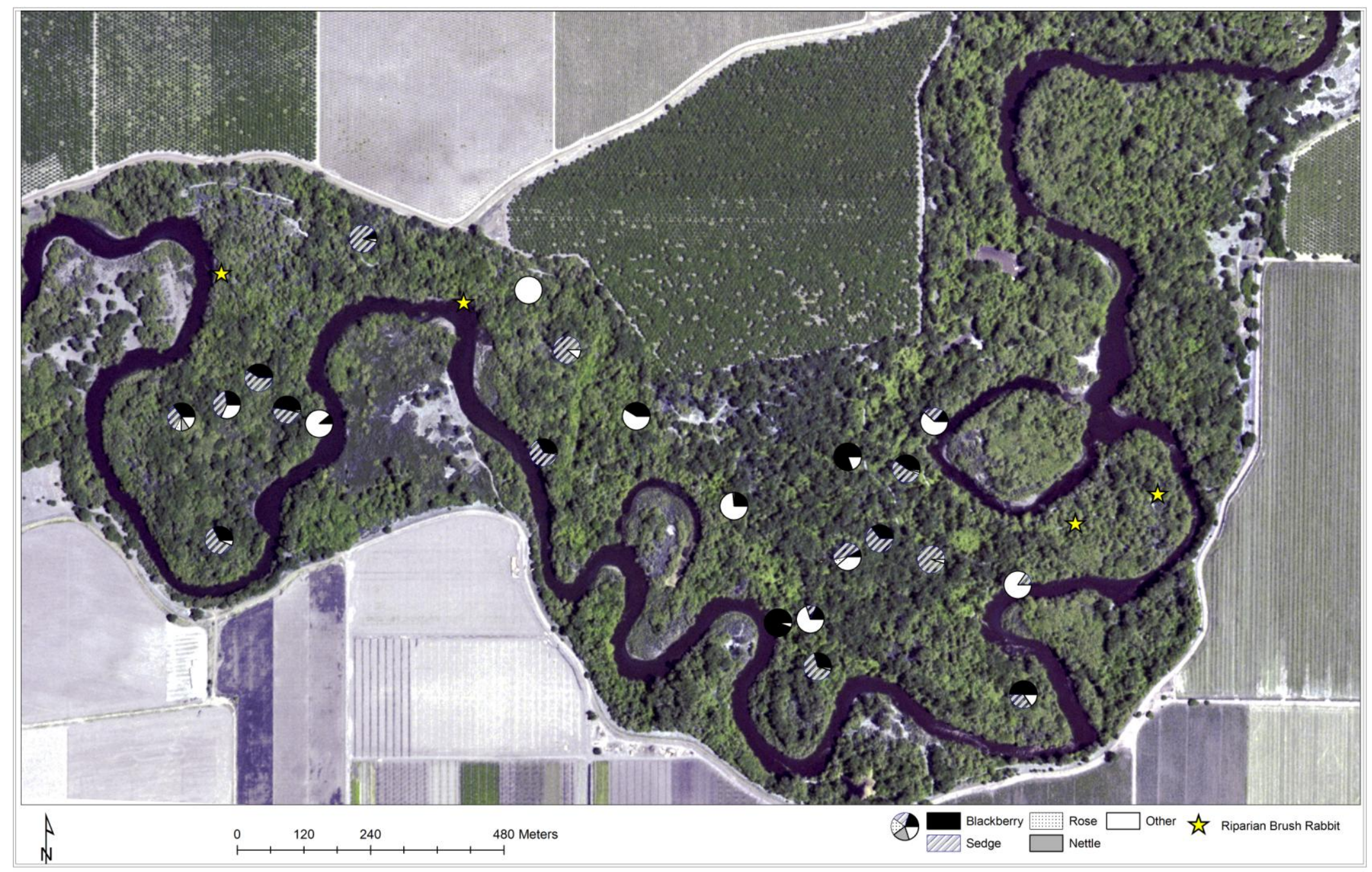

Figure 7. Map of Structure C Understory Plant Species Proportional Cover by Site. Note. ArcMap 9.3 software was used to generate this map. 


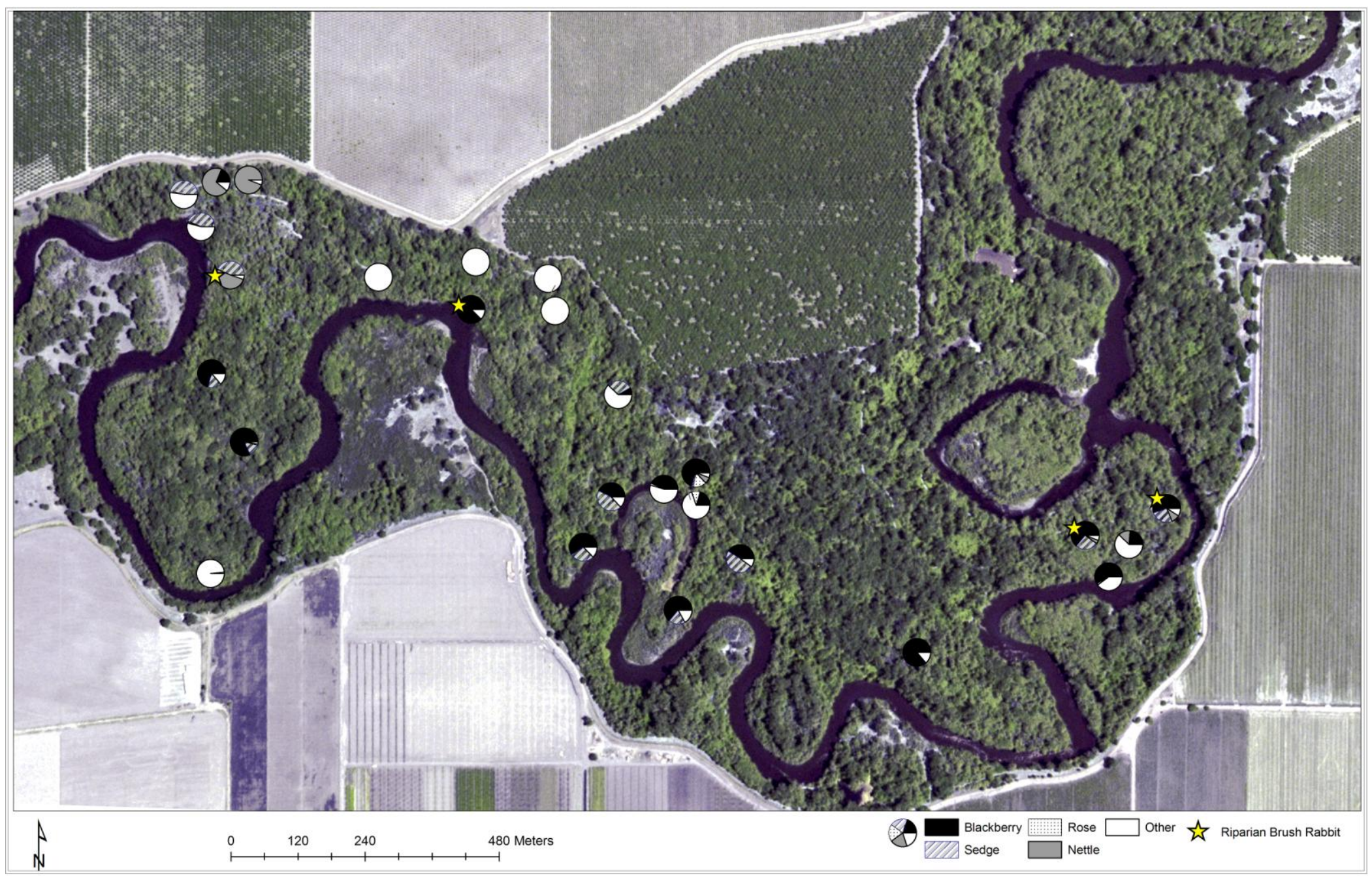

Figure 8. Map of Structure C Understory Plant Species Proportional Cover by Site. Note. ArcMap 9.3 software was used to generate this map. 


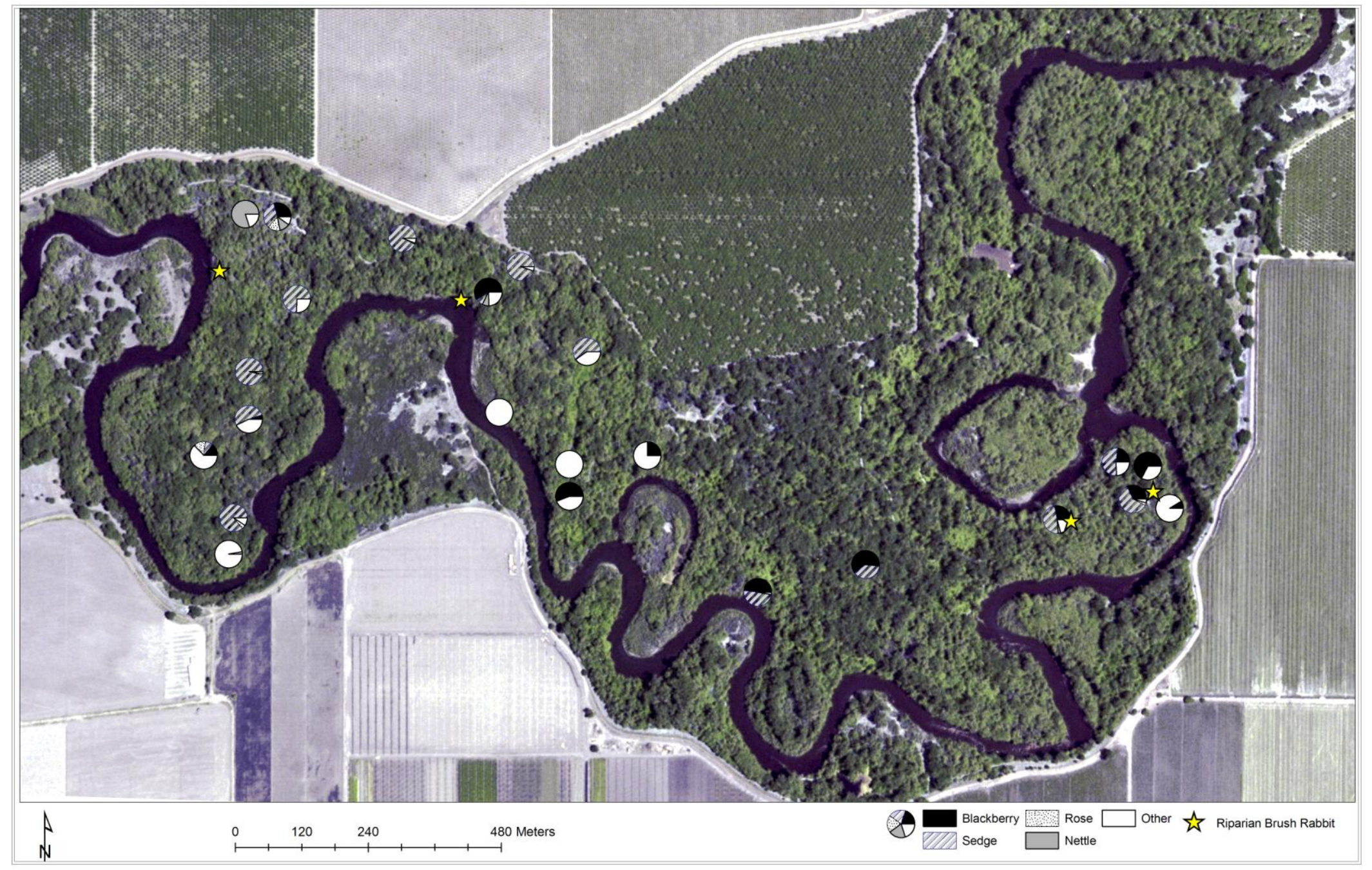

Figure 9. Map of Structure E Understory Plant Species Proportional Cover by Site. Note. ArcMap 9.3 software was used to generate this map. 
When comparing sites based on mammal species presence, no statistically significant difference in vegetation composition and cover was detected (Table 5, Table

7) but a few relationships may warrant further investigation. For instance, sites occupied by rat/mouse spp. had higher cover of California rose when compared sites used by western gray squirrel sites $(\mathrm{F}(1,4)=2.10, \mathrm{p}=0.17)$ and sites absent of animals $(\mathrm{F}(1,4)=2.10, \mathrm{p}=0.11)$. Also, sites occupied by gray fox had a lower cover of golden currant when compared to western gray squirrel occupied sites $(F(1,4)=2.03, p=0.11)$ and sites absent of animals $(\mathrm{F}(1,4)=2.03, \mathrm{p}=0.12)$.

\section{RQ3: Habitat Characteristics of Sites Occupied by the Riparian Brush Rabbit}

The rabbit was detected at four study sites, three in structure D and one in structure E. The presence of a lower, secondary canopy and an absence of a high canopy were characteristic of each of the four sites. The rabbit was not found in the three habitat structures with a high canopy. Collectively, six plant species were recorded for the four sites (Table 8). In the understory, Santa Barbra sedge, Pacific blackberry, and stinging nettle were present at three of the four sites. Comparatively, throughout all the study sites $(n=125)$, Santa Barbra sedge, Pacific blackberry, and stinging nettle were present $54 \%$, $71 \%$, and $28 \%$, respectively. Among all study sites $(\mathrm{n}=125)$, California rose was present in $35 \%$ but absent from all four of the rabbit sites. The raccoon was present in three of the four sites $(75 \%)$ where the rabbit was detected compared to $30 \%$ throughout, gray fox was found in 1 of $4(25 \%)$ where the rabbit was detected and 20\% throughout (26/125). 
Table 12. Comparison of Vegetation Species Present at Sites Occupied by All Animal Species.

\begin{tabular}{|c|c|c|c|c|c|c|c|}
\hline & & $\begin{array}{c}\text { Santa Barbara } \\
\text { Sedge }\end{array}$ & $\begin{array}{l}\text { Golden } \\
\text { Currant }\end{array}$ & $\begin{array}{c}\text { California } \\
\text { Rose }\end{array}$ & $\begin{array}{c}\text { Pacific } \\
\text { Blackberry }\end{array}$ & $\begin{array}{l}\text { Stinging } \\
\text { Nettle }\end{array}$ & Box Elder \\
\hline $\begin{array}{c}\text { All } \\
\text { Animals }\end{array}$ & F-value & 0.21 & 2.03 & 2.10 & 0.20 & 1.57 & 0.39 \\
\hline$\left(F_{1,6}\right)$ & p-value & 0.97 & 0.06 & 0.06 & 0.98 & 0.16 & 0.89 \\
\hline
\end{tabular}

Table 13. Habitat Characteristics of Sites Where the Rabbit Was Found.

\begin{tabular}{|c|c|c|c|c|c|c|c|c|}
\hline Site & Structure & $\begin{array}{l}\text { Santa Barbra } \\
\text { Sedge } \\
\text { Cover }(\%)\end{array}$ & $\begin{array}{c}\text { Pacific } \\
\text { Blackberry } \\
\text { Cover (\%) }\end{array}$ & $\begin{array}{c}\text { Golden } \\
\text { Currant } \\
\text { Cover (\%) }\end{array}$ & $\begin{array}{l}\text { Stinging } \\
\text { Neetle } \\
\text { Cover }(\%)\end{array}$ & $\begin{array}{l}\text { Wild Grape } \\
\text { Cover }(\%)\end{array}$ & $\begin{array}{l}\text { Box Elder } \\
\text { Cover }(\%)\end{array}$ & $\begin{array}{c}\text { Other } \\
\text { Mammals } \\
\text { Present }\end{array}$ \\
\hline 1 & D & 81 & - & - & 96 & 8 & - & $\begin{array}{c}\text { Gray Fox, } \\
\text { Raccoon, } \\
\text { Virginia } \\
\text { Opossum }\end{array}$ \\
\hline 2 & D & - & 72 & 2 & - & - & - & Raccoon \\
\hline 3 & $\mathrm{D}$ & 19 & 40 & 2 & 7 & - & - & Raccoon \\
\hline 4 & $\mathrm{E}$ & 41 & 24 & - & 3 & - & 2 & $\begin{array}{c}\text { Western } \\
\text { Gray } \\
\text { Squirrel }\end{array}$ \\
\hline
\end{tabular}

\section{RQ4: Methodology Comparison: Cameras and Track Plates}

Effectiveness between the two methods were not found to be statistically different for any of the detected species $(F(1,5)=9.477, p=0.091)$. The overall catch per unit effort rate (CPUE) for the track plates and cameras was 0.0078 and 0.0077 , respectively (Table 9). The track plates failed to detect western gray squirrel and the rabbit, while the cameras detected these species at a rate of 0.0011 and 0.0003 , respectively (Table 9).

Track plates were twice as likely to detect Virginia opossum as cameras. Also, the dual 
detection statistic, which reports the percentage of locations where both methods detected the same species, was $3.16 \%$ across all sites. Spatially, the mammal species were distributed throughout the study site (Figures 10-14).

Table 14. Cameras (Cam) and Track Plate (TP) Comparisons Measured by Catch Per Unit Effort (CPUE) for the Rabbit, Fox, Raccoon, and Opossum.

\begin{tabular}{|c|c|c|c|c|c|c|c|c|c|}
\hline & & \multicolumn{2}{|c|}{$\begin{array}{c}\text { Riparian Brush } \\
\text { Rabbit }\end{array}$} & \multicolumn{2}{|c|}{ Gray Fox } & \multicolumn{2}{|c|}{ Raccoon } & \multicolumn{2}{|c|}{ Virginia Opossum } \\
\hline & & Total & CPUE & Total & CPUE & Total & CPUE & Total & CPUE \\
\hline \multirow{4}{*}{ A } & TP & 0 & - & 0 & - & 2 & 0.0017 & 2 & 0.0017 \\
\hline & Cam & 0 & - & 5 & 0.0021 & 5 & 0.0021 & 1 & 0.0008 \\
\hline & Dual Detection & 0 & - & 0 & - & 0 & - & 0 & - \\
\hline & TP & 0 & - & 2 & 0.0017 & 1 & 0.0009 & 0 & - \\
\hline \multirow[t]{3}{*}{ B } & Cam & 0 & - & 2 & 0.0008 & 2 & 0.0008 & 1 & 0.0004 \\
\hline & Dual Detection & 0 & - & 1 & - & 0 & - & 0 & - \\
\hline & $\mathrm{TP}$ & 0 & - & 2 & 0.0017 & 1 & 0.0009 & 2 & 0.0017 \\
\hline \multirow[t]{3}{*}{$\mathrm{C}$} & Cam & 0 & - & 2 & 0.0009 & 5 & 0.0022 & 1 & 0.0004 \\
\hline & Dual Detection & 0 & - & 1 & - & 0 & - & 0 & - \\
\hline & $\mathrm{TP}$ & 0 & - & 3 & 0.0026 & 5 & 0.0043 & 2 & 0.0017 \\
\hline \multirow[t]{3}{*}{ D } & Cam & 3 & 0.0012 & 5 & 0.0020 & 3 & 0.0012 & 3 & 0.0012 \\
\hline & Dual Detection & 0 & - & 0 & - & 1 & - & 0 & - \\
\hline & $\mathrm{TP}$ & 0 & - & 1 & 0.0009 & 4 & 0.0035 & 3 & 0.0026 \\
\hline \multirow[t]{3}{*}{ E } & Cam & 1 & 0.0004 & 6 & 0.0025 & 8 & 0.0033 & 3 & 0.0013 \\
\hline & Dual Detection & 0 & - & 0 & - & 2 & - & 1 & - \\
\hline & TP & 0 & - & 8 & 0.0014 & 13 & 0.0023 & 9 & 0.0016 \\
\hline \multirow{3}{*}{ All Sites } & Cam & 4 & 0.0003 & 20 & 0.0016 & 23 & 0.0019 & 9 & 0.0008 \\
\hline & Dual Detection (Total) & 0 & - & 2 & - & 3 & - & 1 & - \\
\hline & Dual Detection (\%) & - & & $3.33 \%$ & & $4.00 \%$ & & $2.56 \%$ & \\
\hline
\end{tabular}


Table 15. Cameras (Cam) and Track Plate (TP) Comparisons Measured by Catch Per Unit Effort (CPUE) for the Squirrel, Rat/Mouse spp., and All Species.

\begin{tabular}{|c|c|c|c|c|c|c|c|}
\hline \multirow[t]{2}{*}{ Structure } & \multirow[t]{2}{*}{ Method } & \multicolumn{2}{|c|}{ Western Gray } & \multicolumn{2}{|c|}{ Rat/Mouse Spp. } & \multicolumn{2}{|c|}{ All Species } \\
\hline & & Total & CPUE & Total & CPUE & Total & CPUE \\
\hline \multirow{4}{*}{ A } & TP & 0 & - & 3 & 0.0026 & 7 & 0.0061 \\
\hline & Cam & 3 & 0.0013 & 9 & 0.0038 & 22 & 0.0092 \\
\hline & Dual Detection & 0 & - & 1 & - & 1 & - \\
\hline & $\mathrm{TP}$ & 0 & - & 5 & 0.0035 & 7 & 0.0061 \\
\hline \multirow[t]{3}{*}{ B } & Cam & 2 & 0.0008 & 5 & 0.0021 & 12 & 0.0050 \\
\hline & Dual Detection & 0 & - & 1 & - & 2 & - \\
\hline & $\mathrm{TP}$ & 0 & - & 3 & 0.0026 & 8 & 0.0069 \\
\hline \multirow[t]{3}{*}{$\mathrm{C}$} & Cam & 4 & 0.0017 & 1 & 0.0004 & 13 & 0.0054 \\
\hline & Dual Detection & 0 & - & 0 & - & 1 & - \\
\hline & $\mathrm{TP}$ & 0 & - & 3 & 0.0026 & 13 & 0.0113 \\
\hline \multirow[t]{3}{*}{ D } & Cam & 1 & 0.0004 & 5 & 0.0020 & 20 & 0.0083 \\
\hline & Dual Detection & 0 & - & 1 & - & 2 & - \\
\hline & $\mathrm{TP}$ & 0 & - & 1 & 0.0009 & 9 & 0.0078 \\
\hline \multirow[t]{4}{*}{$\mathrm{E}$} & Cam & 5 & 0.0021 & 2 & 0.0008 & 26 & 0.0108 \\
\hline & Dual Detection & 0 & - & 0 & - & 3 & - \\
\hline & $\mathrm{TP}$ & 0 & - & 15 & 0.0026 & 45 & 0.0078 \\
\hline & Cam & 13 & 0.0011 & 22 & 0.0018 & 92 & 0.0077 \\
\hline \multirow[t]{2}{*}{ All Sites } & Dual Detection (Total) & 0 & - & 3 & - & 9 & - \\
\hline & Dual Detection (\%) & - & & $4.00 \%$ & & $3.16 \%$ & \\
\hline
\end{tabular}




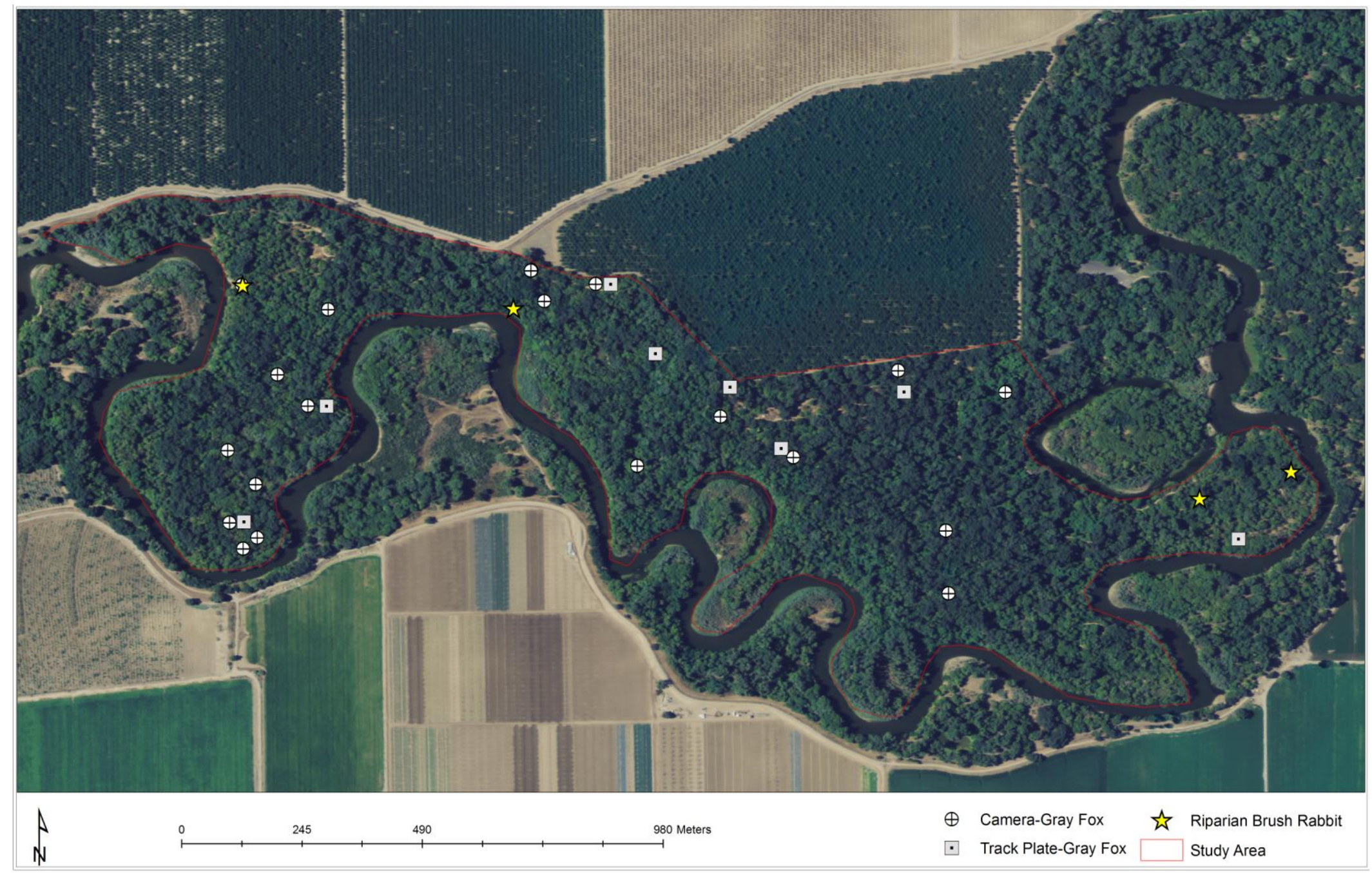

Figure 10. Map of Gray Fox Presence. Note. ArcMap 9.3 software was used to generate this map. 


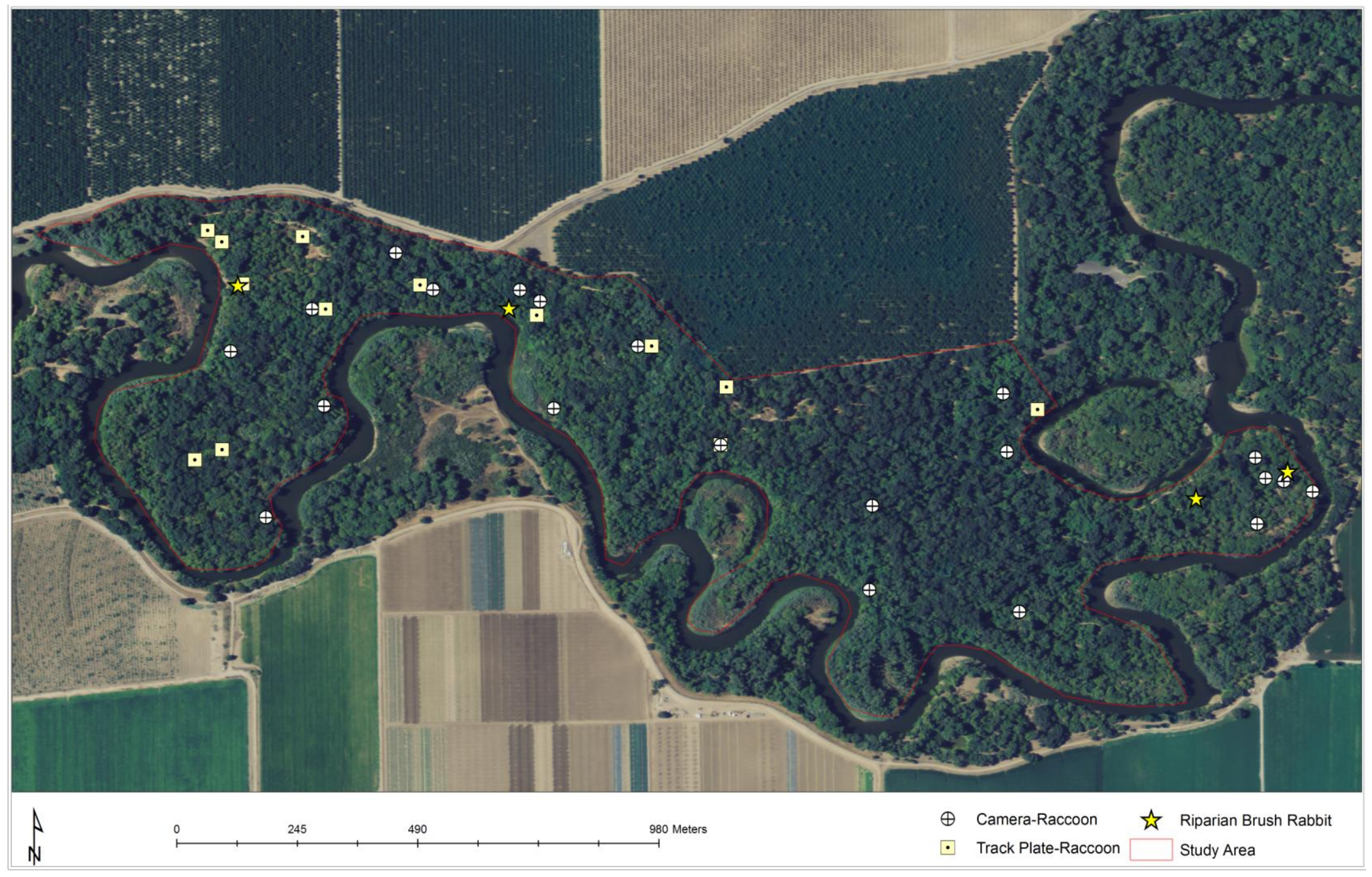

Figure 11. Map of Raccoon Presence. Note. ArcMap 9.3 software was used to generate this map. 


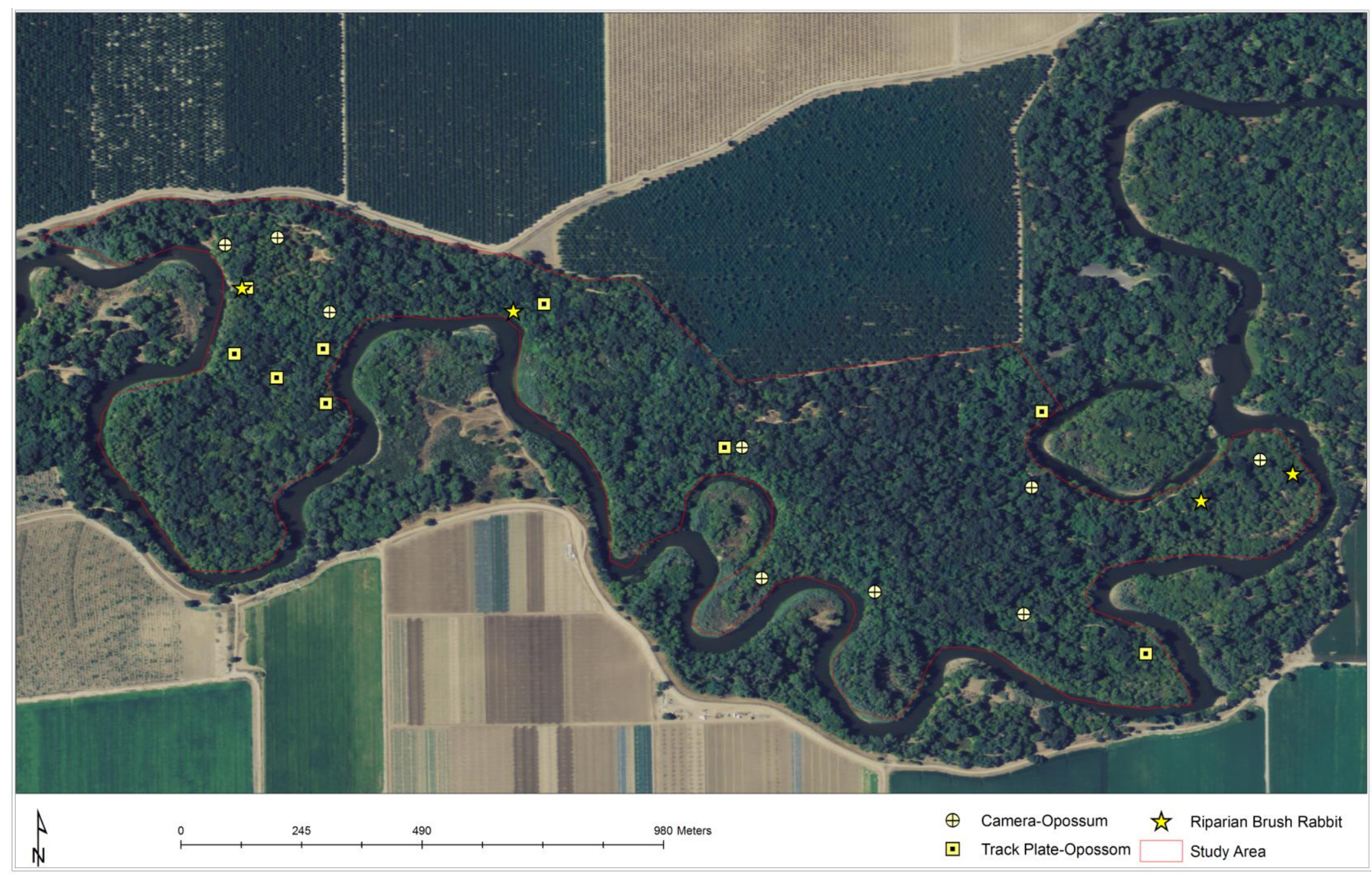

Figure 12. Map of Opossum Presence. Note. ArcMap 9.3 software was used to generate this map. 


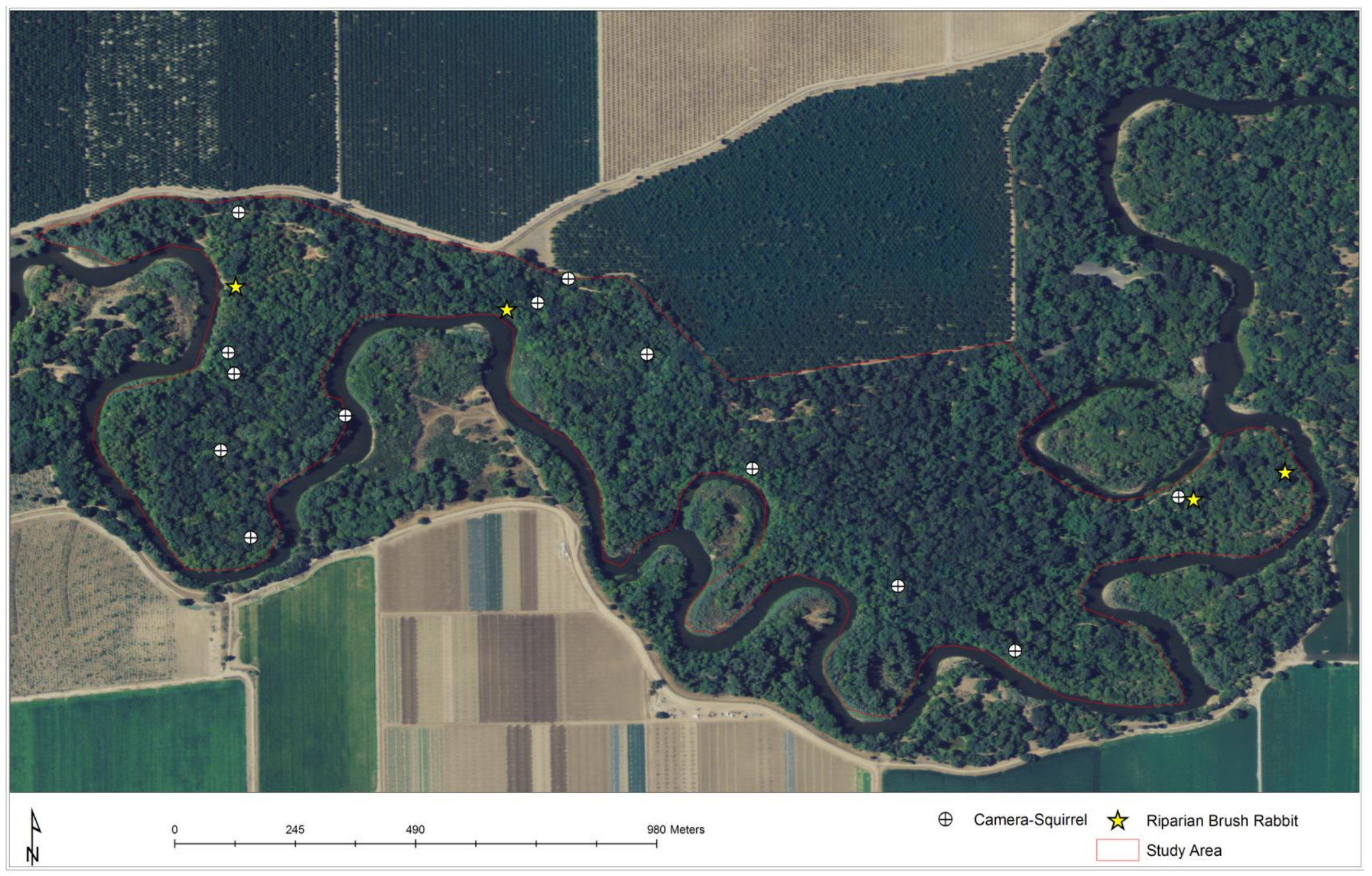

Figure 13. Map of Western Gray Squirrel Presence. Note. ArcMap 9.3 software was used to generate this map. 


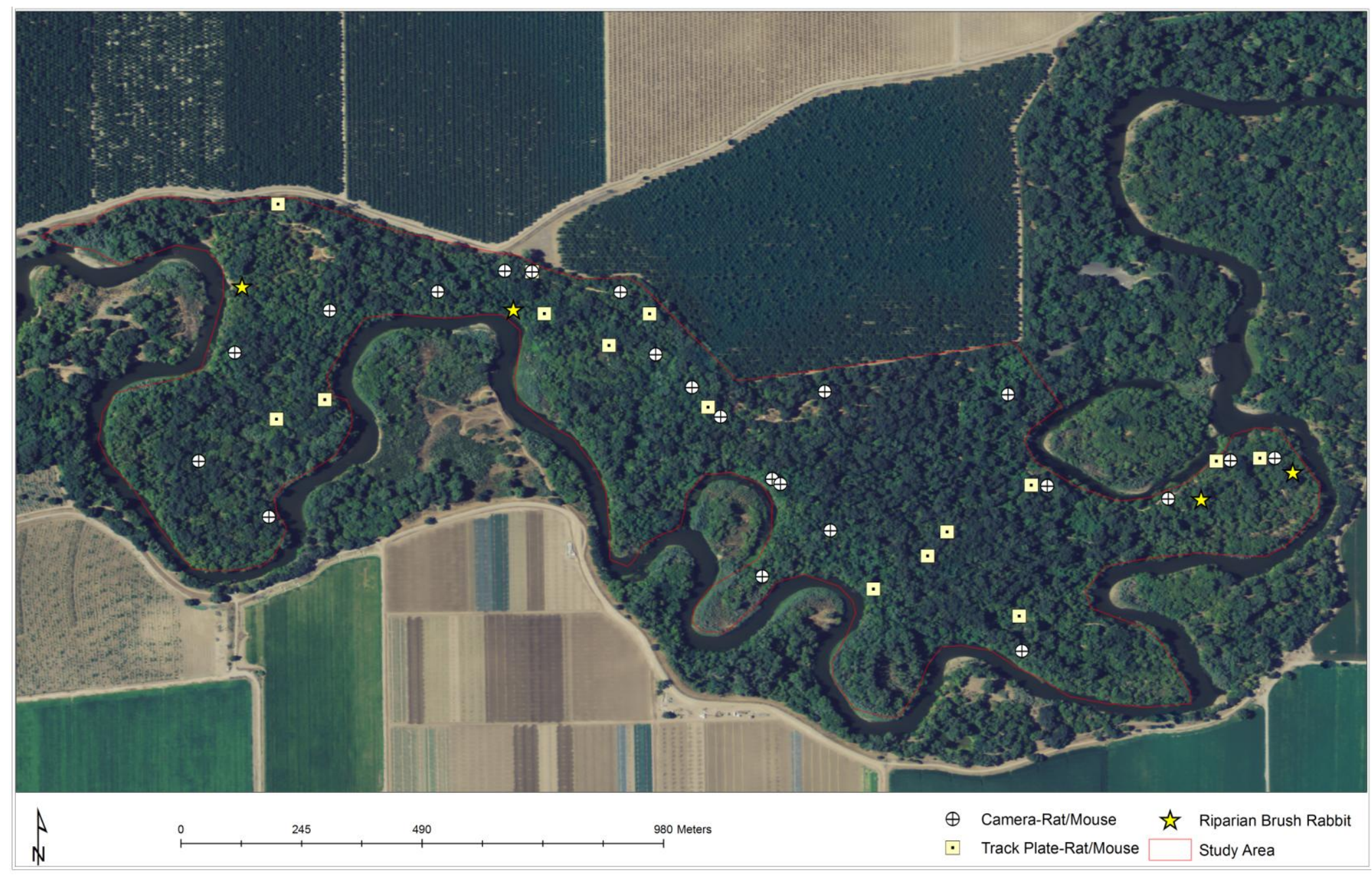

Figure 14. Map of Rat/Mouse Presence. Note. ArcMap 9.3 software was used to generate this map. 


\section{Discussion}

\section{Comparison to Past Studies}

Williams and Basey (1986) measured canopy cover, ground cover, and understory cover at 30 sites--10 occupied by the rabbit, 10 occupied by desert cottontail, and 10 unoccupied--and found few willows where the rabbit was present. My data support these findings as none of the four sites occupied by rabbits had willow spp. However, less than seven percent of all sites in my study had willow spp. suggesting that this plant is not overly abundant within Caswell Memorial State Park. William and Basey (1986) also measured leaf litter and found higher levels at rabbit sites. The authors speculated that these two factors, few willows and high amounts of leaf litter, are characteristic of areas that do not flood regularly. Therefore, rabbits are occupying areas that allow them to avoid flood waters.

Both this thesis study and the study by Williams and Basey (1986) found over $20 \%$ cover of native blackberry at rabbit occupied sites. The rabbit may prefer sites with native blackberry since this plant can grow over one meter in height providing cover and protection from predators. On the other hand, my rabbit-occupied sites had no California rose present, while Williams and Basey (1986) found 17\% cover on average. This disparity may be due to my small sample size and the low rabbit population and may not be a true reflection of the rabbit's preference, as both blackberry and California rose appear to be ideal for predator protection, providing cover and a barrier. For example, Williams (1993) noted that the rabbit hides in areas so thick with vegetation that he was unable to see the reflective taped placed on the animals during a census. Prior to this 
study, I frequently observed the rabbits in rose thickets in the Park, although these sightings are anecdotal. Throughout the study sites, California rose was fairly common occurring in $32 \%$ of the sites, covering $16 \%(\mathrm{SD}=20.16)$ where found.

Williams and Basey (1986) also found close to $10 \%$ coyote brush cover at their rabbit-occupied sites. This plant species was absent from my occupied sites, but again was also limited in distribution throughout the Park, occurring at only 2 of 125 sites. The authors also found that box elder, a medium sized tree, was the most prevalent canopy species. Although I did not directly measure cover of canopy species, the habitat structure classes used to stratify my sample were partly based on the presence of trees, understory and canopy. Therefore, structures D and E were partly defined by the presence of medium sized trees, commonly box elders. Since all rabbit detections were within these two structures, the sites can be characterized as having medium sized trees while lacking a high canopy. The rabbit may select sites that are devoid of a high canopy because the increased sunlight allows for thicker understory growth and higher cover resulting in better predator protection and forage. Without a high canopy, avian predators, which have reportedly accounted for $25 \%$ of rabbit predator mortality (Hamilton et al., 2010), also are denied a hunting perch.

\section{Trail Proliferation and the Rabbit}

Within the Park, I observed the rabbit most frequently in the western portion within the trails-only area. This trail system is approximately $6.5 \mathrm{~km}$ in total length, and trail width is on average 3-4 m (Figure 1). The peak hiking season is the summer on the weekends, while numbers of weekday visitors are low throughout the year. In addition to 
hiking, the trails are used as emergency and maintenance vehicle access routes. In their review of 40 research studies measuring responses of mammals to the presence of either off highway vehicles or hikers, Boyle and Samson (1985) found that $72 \%$ documented negative effects on these species. These negative effects can range from habitat fragmentation, habitat loss, and changes animal behavior and species composition including the introduction of invasive species.

Although this thesis research did not collect data on the influence of trails on rabbit behavior, some evidence suggests that trails and the accompanying human presence negatively affects the rabbit population. Orr's (1940) observations confirm that brush rabbits alter their behavior by fleeing into the brush when a disturbance occurs. The rabbits waited six minutes, on average, before resuming foraging activities. If this reaction is typical in rabbits, then constant human presence may reduce foraging times resulting in lower body weights and reproduction rates. The rabbit may also seek habitat farther away from trails and avoid the areas near trails. In addition to changing animal behavior, trails have been found to facilitate invasive plant species establishment (Dickens, Gerhardt, \& Collinge, 2005). A shift in plant species and communities away from the native habitat could exert further downward pressure on the Park's rabbit population.

\section{Flood Regime}

Prior to flood control measures, most of the surrounding land of the Park was used for cattle pastures with uneven topography. The first Melones Dam, built in the 1920s, provided farmers flood protection which led to more intense agricultural practices 
within the river's floodplain. The much larger New Melones Dam, completed in 1979, intensified the development further because flood protection was more stable. Farmers were more confident that flooding would not damage their investments and as a result leveled the ground and cleared remaining patches of vegetation in order to plant row crops and orchards. The cattle pastures, with higher elevations and less managed vegetation cover, were more hospitable to the rabbit, especially during flooding, providing them escape habitat during high waters (Williams \& Basey, 1986). In addition, levees were built parallel to the river confining the water during flooding and not allowing it to disperse across the floodplain. The result is higher levels of water within the levee banks and consequently in the Park.

In the winter of 1985-1986, Williams (1993) reported "severe flooding" at the Park and estimated the rabbit population at 10 individuals. In 1988, population estimates ranged from 88 and 540 (95\% confidence interval) rabbits and to 170 and 608 rabbits in 1993 (Williams, 1993), a period of no flooding. In the winter and spring of 2004-05, Modesto experienced $38.6 \mathrm{~cm}$ of rainfall, exceeding the mean annual rainfall of $31.6 \mathrm{~cm}$ (NOAA, 2006). Approximately $8 \mathrm{~km}$ downstream, Hamilton et al. (2010) reported that survival of the rabbit at the Refuge was "strongly impacted" by flood events in March, May, and June of 2005 caused by reservoir releases. In the winter and spring of 2005-06, the mean annual rainfall was again exceeded in Modesto, amounting to $34.52 \mathrm{~cm}$ (NOAA, 2006). A flood event followed on the Refuge and again drastically impacted the rabbit population. Anecdotally, the results appeared similar at the Park where flood waters seeped into the Park, inundating approximately $40 \%$ of the habitat (personal 
observation). Prior to the flooding of 2006, I frequently observed rabbits along the trails. Over the next 22 months after the flooding, I made frequent visits to these areas and rarely saw any rabbits in these locations. These observations correlate with my data where only 4 of the 125 sites had rabbit occurrences. Unfortunately, the population still appears to be suppressed since park staff reported only seeing a single rabbit between 2008-2010 (J. J. Ramsour, personal communication, July 25, 2010).

Flooding is predicted to become more intense and frequent in the coming years due to the changing climate. Historically, streams and rivers in the West receive the highest amount of flow from spring and summer snow melt (Stewart, Cayan, \& Dettinger, 2003). Data have shown that winter and spring temperatures are rising in the West, and precipitation proportionally is shifting from snow to rain (Knowles, Dettinger, \& Cayan, 2006; Stewart et al., 2003). The rising spring temperatures are also resulting in less snow and increased rain with quicker melting of the snow pack. At the current rate, stream flows are projected to begin 20-40 days earlier (Stewart et al., 2003), and the snow pack is expected to be reduced by 50 percent in the Sierra Nevada by century's end (Miller, Bashford, \& Strem, 2003). The resulting reduction in natural storage in the snow pack will lead to increased pressures on reservoirs likely leading in turn to larger, more frequent water releases and consequently more flooding downstream (Brekke, Miller, Bashford, Quinn, \& Dracup, 2004; Miller et al., 2003). It should be noted that some models predict decreased inflow and storage releases (Brekke et al., 2004).

Whether the flood regime remains at its current state or changes, a lack of high water refugia remains one of the greatest threats to the Park's rabbit population. The 
2006 flood event was mild when compared to past floods, yet the rabbit appears to have been strongly impacted. High water refugia has been essential to similar rabbit species (Zollner et al., 2000) and appears to be important for the riparian brush rabbit survival.

\section{The Park and Mesopredator Release Theory}

The mesopredator release theory may be applicable for the Park. The conversion of the Central Valley's native habitats to agriculture and urban development has caused changes in the relationships and abundances of predator and prey species especially reducing numbers of large predators. Predicting how these effects will cascade through the food web is difficult. Historically, the coyote was one of the top predators in this ecosystem but large scale land use changes have reduced their numbers. The absence or reduction of the coyote may lead to a population increase of mesopredators. Mesopredators detected during this thesis study included the gray fox and raccoon. Although evidence is lacking on whether raccoons predate on rabbits, traces of Sylvilagus spp. have been reported in raccoon scat (Baker, Coleman, Newman, \& Wilke, 1945). A potential increase in raccoon populations is expected to have a negative effect on their prey species including the rabbit. With fewer rabbits, foxes and raccoons will have to shift their diets to other species, such as the black rat and western tree squirrel. Live trapping efforts have found the exotic black rat widespread and abundant throughout the Park (personnel observation). The western tree squirrel is common, as well, and has been observed collecting walnuts in the orchard adjacent to the Park (personnel observation). The food web for the Park has likely been altered by the introduction of the black rat and the diet subsidization of the western gray squirrel; mesopredator population increases 
may be the result. It should be noted this thesis study did not test this theory, rather it only documents the presence of these mammals within the Park (Table 9).

\section{Comparison of Cameras and Track Plates}

The results of the two data collection methods were similar. Although the track plates did not detect any rabbits, the sample size was also low for the cameras, indicating a small population size and low likelihood of detection. In other words, the low rabbit detection may be attributed to chance rather than avoidance. In order to detect statistically significant differences, a power analysis indicated a sample of 480 samples would be needed $(\mu=.032, s=0.17670, \beta=0.20)$. In general, the results indicate either method would be appropriate for detecting medium to small mammals within a riparian forest

ecosystem. Although the results were similar, these two methodologies did differ in cost, data quality, and labor.

Track plates have proven useful and effective in detecting mammal presence. Their popularity is due mostly to the economical advantage of the materials as compared to other data collection methods. For instance, Connors et al. (2004) reported they could produce a track plate for $\$ 0.24$. Glennon et al. (2002) used plates and a tube structure at a cost just over $\$ 2.00$ each. Therefore, the investment is minimal which can be advantageous if data collection is going to occur in areas where vandalism or theft may take place. Comparatively, the cameras I used were approximately $\$ 140.00$ each, without batteries, and one was stolen during data collection.

Data quality was higher when using cameras to detect mammal presence. Most importantly, species identification was easier and less ambiguous with the cameras. The 
species, excluding the rats and mice, could be confidently identified in short period of time. Tracks sometimes took several minutes to interpret and multiple, overlapping tracks also made the identification process more difficult. In fact, the more activity there was at a site, the more difficult track identification became. An increase of activity for cameras was never an issue as the memory card was never full. Additionally, more data can be collected using cameras including a time/date stamp. The higher end models even record temperature and moon phases. Any additional data collected outside of that needed can be easily identified and discarded. Data recovery for track plates on the other hand, has to be precise since the timing of the tracks is unknown. This is a draw back because delays are not uncommon.

The track plates took more time to prepare since I had to cut them to size, mix the graphite, let them dry and delicately transport them. In the field, I had to modify a small patch of habitat in order for the track plate to sit level. Once I became familiar with the cameras they were easy to program, quicker to set up, and habitat modifications were not required. Lastly, the cameras are more durable. Unlike track plates, curious mammals and storm events do not easily disturb cameras. Although none of the track plates were in the field during a storm event, some plates were disturbed.

\section{Study Recommendations}

In 2004 and 2005, I frequently observed rabbits in several locations throughout the Park. After the flood event in 2006, sightings declined drastically from daily occurrences to just two over a several month period. By the time I conducted my study in the summer of 2007, rabbit sightings were extremely rare. This anecdotal information 
was corroborated by the low detection results from my study. If this study were conducted prior to the flooding event, rabbit detections would certainly have been higher. As a result, the potential of this study was never fully realized. Many questions about rabbit habitat use still remain unanswered and additional research is needed. With a few adjustments and proper timing, this study design could expand our understanding of the vegetation components required by the rabbit and the areas of the Park the rabbits are occupying. The research will be more informative if it is conducted when the population has expanded, which will allow for higher sample sizes. This population expansion could be verified by using a pilot study, morning and evening trail hikes, or interviews with park staff.

A few changes to the methods are recommended for future studies. I would rely exclusively on cameras since this research has indicated they are more reliable at detecting rabbits. The focus should remain on habitat characteristics at ground level with the addition of a bare ground and leaf litter measurement. Additionally, close attention should be paid to canopy species and cover since some of the data suggests that the rabbits avoid areas with higher canopies (Williams \& Basey, 1986). This avoidance could be due to raptor predation (Hamilton et al., 2010) and therefore, a raptor study that documents presence, habitat use, and population trends could be useful in explaining rabbit habitat selection.

While vegetation, especially cover, is important to the rabbit, a future study should also refine the parameters to include topography and distance to trails. Stratification by topography or elevation will require more detailed mapping. 
Considering the subtle elevation differences in the Park, a topographical map depicting one foot contours would be required. The measure of rabbit presence by elevation and trail proximity will lead to a greater understanding of their importance to the rabbit and have direct and clear management implications for the Park.

An experimental study design should also be implemented for any newly acquired lands in need of restoration. All restoration designs should include high ground refugia, or "bunny mounds" with experimental vegetation treatments based on the presence and absence of secondary and high canopy species. As indicated by this study and that by Williams and Basey (1986), rabbits may be selecting sites with secondary canopy and avoiding areas with higher canopies. If this behavior is verified through an experimental design and the presence of high canopy species are increasing within the Park, this habitat may fail to continue to support the rabbits in the future. Also, shrubby vegetation could be planted on these mounds using varying levels of Pacific blackberry, California rose, and golden currant cover.

A more robust monitoring program for the rabbit population should also be explored. Williams (1993) conducted a baseline study using live traps. He speculated that his results were a reliable estimate of the non-breeding population and likely reflected the peak carrying capacity of the Park. He also identified 31 sites where rabbits were using "communal toilets." Since live-trapping has limitations and can be labor intensive, his intention was for these pellet sites to be monitored annually and provide an index of the population. This approach was never implemented and it should be explored. As an alternative, cameras can also provide an index of rabbit abundance. 
Live trapping could then be performed every three to five years to corroborate the results (Williams, 1993). Park managers should review Williams (1993) and consider replicating his methods for an annual monitoring program or exploring a methodology that suits their needs. The emphasis should be on the ease of regular replication while remaining cost effective. Ultimately, the goal would be to create an action plan managers can use to respond to prolonged population contractions. Anecdotal evidence can assist in the interpretation of more formal study findings and should be collected in a database.

\section{Management Recommendations}

Each of the three riparian brush rabbit populations remain isolated from each other and are highly vulnerable to extinction. The introduced population at the Refuge is being intensely cared for by rabbit biologists but the future remains in question, especially considering recent harmful events (Hamilton et al., 2010). The Paradise Cut population is small in size and remains under the care of private citizens (Williams et al., 2008). The Park population continues to be endangered as a result of being confined to a small area that experiences regular flood events. The Park is the last known natural rabbit population that is managed by the government and is therefore a critical component to the recovery of this species. Several options are available to wildlife managers that could improve the chances for recovery of the riparian brush rabbit. Several options have been identified and prioritized below:

1) Acquire and Restore Habitat. Managers can use the vegetation data from this thesis research (Table 4) as a model to evaluate the suitability of existing habitat for rabbits or to guide restoration efforts on acquired lands. 
a. Acquire or obtain a conservation easement for farmland adjacent to the Park. More specifically, priority should be given to the 36.50 ha parcel adjacent to the Park's trails-only area within the levee system (Figure 4). Currently, this land is planted with walnut trees. The restoration of this parcel to rabbit habitat would reduce the overall edge effects within the Park. Further, since this is one of only two parcels of farmland within the confines of the levee system and adjacent to the Park, the rabbits would not have to transverse a potentially hostile, vegetation-free levee, which may act as a barrier to rabbit movement. The result would be either the restored habitat is never colonized or, if rabbits are introduced, the two populations will not interact with human assistance.

b. Identify, evaluate, and acquire existing riparian forest habitat within and outside of the rabbit's historical range. Examine the remaining habitat fragments and compare the habitat to the Park's vegetation composition.

c. Acquire the land where the Paradise Cut population lives. Since this is one of only two natural populations of the rabbit, management of the habitat needs to be closely monitored.

2) Increase High Water Refugia. The low detection rate of rabbits during this thesis study followed the flood event of 2006, underscoring the need for high water refugia inside and outside of the Park.

a. Acquire adjacent farmland to provide for the construction of high water refugia while preserving the Park's habitat. The 36.50 ha parcel currently 
planted as a walnut orchard is favorable since it is within the levees and may remain dry during minor flood events since it is relatively far from the river.

b. Seek an agreement with the Lower San Joaquin Levee District to allow vegetation to become established on the adjacent levees. Rabbits have been observed in re-vegetated levees (Rentner \& Lloyd, 2010). The establishment of vegetation on levees would allow managers to take advantage of existing high water refugia allowing rabbits to escape a flood's rising waters while also being concealed from would be predators.

c. Build and vegetate "bunny mounds" in disturbed areas of the Park (Figure 15). The mounds should match the height of the ten foot levees that parallel the Park. Within the Park, managers should consider enhancing lower quality areas by building mounds using imported soil and planting with favorable native species such as pacific blackberry, California rose, golden currant, and Santa Barbara sedge.

i. The old burn pile is the most attractive site for "bunny mound" construction for several reasons. Most importantly, it is surrounded by native vegetation and within the largest habitat fragment of the Park. Outside of annual, weedy plants, the site is currently clear of vegetation to allow for the temporary stockpiling of brush material and is not likely utilized by the rabbit. Therefore it would not result in any temporary loss of usable habitat. There is also an access road to the site which would accommodate construction traffic and restoration 
activities. While the area is relatively large $(0.0952 \mathrm{ha})$, it is believed the rabbits' density is between 1.5-3.00/ha (Basey, 1990; Williams, 1993), so this area would not likely provide shelter to a large number of rabbits. Park staff would need to adopt another staging site for brush materials.

ii. Eradicated invasive species sites are also available. For instance, the area to the west was heavily infested with tree of heaven (Ailanthus altissima) throughout the 1990s. Beginning in 1998, this invasive tree population was removed. Although some native plant recruitment has occurred and rabbits have been shown to use this area, it remains in early successional stages with other exotic plant species invading, mostly thistles. These areas could be surveyed for rabbit presence and be considered for "bunny mound" construction.

iii. Outside of the study area but within the Park, a few more opportunities exist for higher ground construction. The most underutilized area by humans and rabbits is the overflow parking lot since it is paved with asphalt and only opened a few times a year during peak use. Similar to the burn area, it would not result in temporary habitat loss and the access road is conducive to construction activities.

iv. The largest area in the Park that is not likely rabbit habitat is the picnic/day use area (0.9729 ha) which is mowed to keep vegetation low. Importing soil and raising the elevation by a few meters is very 
feasible since access to the area is provided by the main road. The challenge would be providing both the cover required by the rabbit and an area where visitors can recreate.

d. Elevate trails to provide connectivity between "bunny mounds". If the hiking trails are raised, the area underneath could act as corridors between mounds (Rentner \& Lloyd, 2010).

e. When large trees fall, leave the main stems where they lie or relocate them strategically throughout the Park to provide high ground. Often, fallen trees are cleared within the park to reduce fuel in the event of a wildfire or are used for firewood. If wildfire remains a concern, the brushy canopy of the fallen tree could be removed, leaving the main stems. The main advantage of this measure is that it could be implemented immediately and should be effective since rabbits have been reported climbing low lying trees during past flood events (Basey, 1990; Williams \& Basey, 1986).

f. Conduct a survey of the Park that produces detailed contours. Current topographical maps are too coarse to provide useful elevation data. A survey should be completed that produces one foot contours which will allow managers to identify high ground. Appropriate protection and possible enhancement measures could then be implemented in these areas. During the severe 1997 flood event, only 15\% of the park was not submerged by flood waters (San Joaquin County Multi-Species Habitat Conservation and Open 
Space Plan, 2000). Managers need to ensure that adequate cover exists and escape avenues to these areas are intact for future events.

3) Habitat Protection and Enhancement within the Park

a. Perennial shrub species, e.g., Pacific blackberry and California rose should be used in restoration projects.

b. Brush thickets, especially Pacific blackberry and California rose, should be considered the most critical to the survival of the rabbit and protected and promoted when possible.

c. Evaluate existing fencing program in the campground and replace fencing with a more substantial barrier to discourage trampling of vegetation. The campground's lack of observable rabbit activity over the past decade suggests habitat enhancement is warranted. Over time, campers continued to trample the habitat on the perimeter of the campsites, enlarging campsites far beyond their original boundaries. In 2005 , managers wisely erected fences to clarify the limits of use and prevent further destruction. Unfortunately, the fence in many areas is in a state of disrepair and will likely be targeted for removal soon, leaving the habitat vulnerable to intrusion. An assessment of the fence's effectiveness and current condition should be completed and a more substantial and aesthetic fence erected that will persist.

d. Enhance shrub habitat within the campground area. Areas within the campground behind protected fencing should continue to be targeted for habitat enhancement in order to expand useable habitat for the rabbit. 
e. If a negative correlation between high canopy and rabbit presence can be established through further study, discourage the establishment of high canopy tree species in rabbit habitat areas.

4) Rabbit Population Monitoring and Management

a. Develop a plan to guide long-term management of the Park for the rabbit. This plan can be phased in by short, medium, and long-term goals. To help ensure success, this plan should have "buy in" from all disciplines of Park operations and be widely available so subsequent managers understand the long term goals in the Park.

b. A simplified but formal monitoring protocol (cameras, pellet counts) should be implemented annually.

c. A more robust monitoring program (live trapping) should be used less often (every 3-5 years) to corroborate the aforementioned monitoring findings. For more information, review the study and recommendations by Williams (1993).

d. A protocol for documenting the anecdotal data needs to be developed and training provided to all Park staff.

e. Track both anecdotal evidence and formal survey results in an electronic database. Annually, summarize the data found and make the data widely available for internal and external reference.

f. Once the high water refugia are in place, compare the genetic information between the Park rabbits and the Refuge rabbits and introduce new rabbits to 
the Park if the population remains suppressed and the genetic analysis indicates the rabbit population is inbred.

g. Prohibit new trail construction. Since the Park is home to one of the last known riparian brush rabbit populations and mammals have been shown to alter behavior in the presence of humans, the trail system should be managed with careful consideration to this species.

h. In areas with high levels of rabbit activity, consider full or partial (time of day) closure of trails to humans. Managers should identify the areas where the rabbit has been consistently observed and close trails nearby. If trail closure is not feasible, then restrict hiker's access during the most sensitive times of the day (morning and evening).

i. Review current trail layout and eliminate trails, if feasible. 


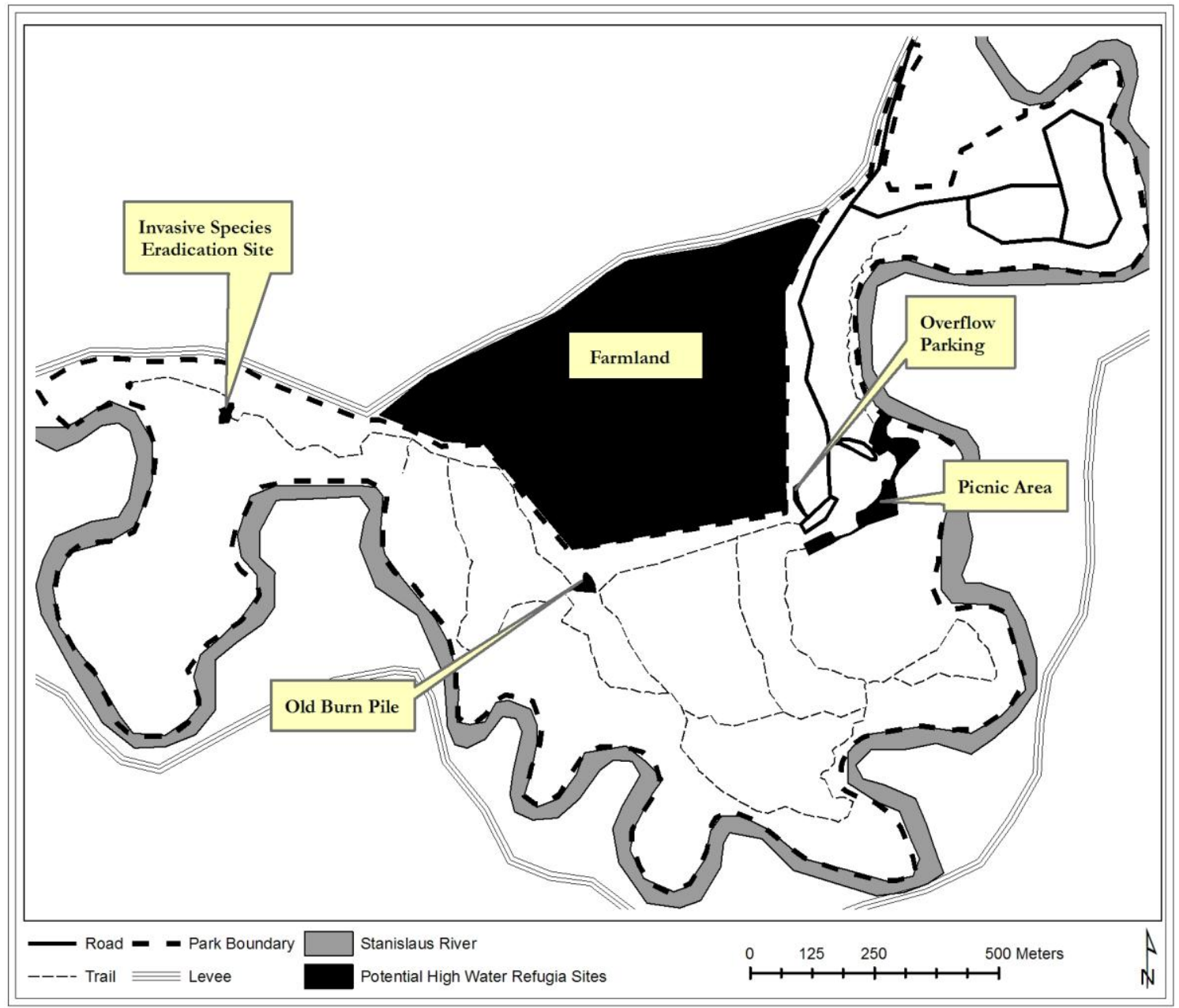

Figure 15. Potential High Water Refugia, "Bunny Mounds," Sites. These sites are currently free of vegetation and have little value to the rabbit. Soil could be imported to establish high ground during flood events. The trails could also be raised to allow additional refugia and connectivity. Note. ArcMap 9.3 software was used to generate this map. 


\section{References}

Baker, R. H., Newman, C. C., \& Wilke, F. (1945). Food habits of the raccoon in Eastern Texas. The Journal of Wildlife Management, 9, 45-48.

Basey, G. E. (1990). Distribution, ecology, \& population status of the riparian brush rabbit (Sylvilagus bachmani riparius). Master's Thesis. California State University, Stanislaus.

Bond, B. T., Wes Burger, L., \& Leopold, B. D. (2000). Survival of cottontail rabbits (Sylvilagus floridanus) in Mississippi and an examination of latitudinal variation. American Midland Naturalist, 145, 127-136.

Bonham, C. D. (1989). Measurements for terrestrial vegetation. New York, NY: WileyInterscience Publications.

Boyle, S. A. \& Samson, F. B. (1985). Effects of nonconsumptive recreation on wildlife: A review. Wildlife Society Bulletin, 13, 110-116.

Brekke, L. D., Miller, N. L., Bashford, K. E., Quinn, N. W. T., \& Dracup, J. A. (2004). Climate change impacts uncertainty for water resources in the San Joaquin River Basin, California. Journal of the American Water Resources Association, 40, 149164.

California State Parks. (2010). Caswell Memorial State Park. Retrieved August 31, 2010, from http://www.parks.ca.gov/?page_id=557.

Chapman, J. A. \& Litvaitis, J. A. (2003). Eastern cottontail. In Feldhammer, G. A. Thompson, B. C., and J. A. Chapman, Wild mammals of North America: Biology, management, and conservation. Baltimore, MD: Johns Hopkins University Press.

Clevenger, A. P., Chruszcz, B., \& Gunson, K. (2001). Drainage culverts as habitat linkages and factors affecting passage by mammals. The Journal of Applied Ecology, 38, 1340-1349.

Connors, M. J., Schauber, E. M., Forbes, A., Jones, C. G., Goodwin, B. J., \& Ostfeld, R. S. (2004). Use of track plates to quantify predation risk at small spatial scales. Journal of Mammalogy, 86, 991-996.

Crooks, K. R. \& Soule, M. E. (1999). Mesopredator release and avifaunal extinctions in a fragmented system. Nature, 400, 563-566.

Cutler, T. L. \& Swann, D. E. (1999). Using remote photography in wildlife ecology: A review. Wildlife Society Bulletin, 27, 571-581. 
Danielson, B. J. (1991). Communities in a landscape: The influence of habitat heterogeneity on the interactions between species. The American Naturalist, 138, 1105-1120.

Diaz, M., Torre, I., Peris, A., \& Tena, L.. (2005). Foraging behavior of wood mice as related to presence and activity of genets. The Journal of Mammalogy, 86, 11781185.

Dickens, S. M., Gerhardt, F., \& Collinge, S. K. (2005). Recreational portage trails as corridors facilitating non-native plant invasions of the boundary waters canoe area wilderness (U.S.A.). Conservation Biology, 19, 1653-1657.

Fa, J. E., Romero, F. J., \& Lopez-Paniagua, J. (1992). Habitat use by parapatric rabbits in a Mexican high-altitude grassland system. The Journal of Applied Ecology, 29, 357-370.

Fahrig, L. \& Merriam, G. (1994). Conservation of fragmented populations. Conservation Biology, 8, 50-59.

Glennon, M. J., Porter, W. F., Demer, C. L., \& Kie, J. G. (2002). An alternative field technique for estimating diversity of small-mammal populations. Journal of Mammalogy, 83, 734-742.

Gompper, M. E., Kays, R. W., Ray, J. C., Lapoint, S. D., Bogan, D. A., \& Cryan, J. R. (2006). A comparison of noninvasive techniques to survey carnivore communities in northeastern North America. Wildlife Society Bulletin, 34, 1142-1151.

Hacket, H. M., Lesmeister, D. B., Desanty-Combes, J., Montague, W. G., Millspaugh, J. J., \& Gompper, M. E. (2007). Detection rates of eastern spotted skunks (Spilogale putorius) in Missouri and Arkansas using live-capture and noninvasive techniques. American Midland Naturalist, 158, 123-131.

Hamilton, L. P., Kelly, P. A., Williams, D. F., Kelt, D. A., \& Wittmer, H. U. (2010). Factors associated with survival of reintroduced riparian brush rabbits in California. Biological Conservation, 143, 999-1007.

Hamm, K. A., Diller, L. V., Klug, R. R., \& McDonald, T. L. (2003). Spatial independence of fisher (Martes pennanti) detection at track plates in Northwestern California. American Midland Naturalist, 149, 201-210.

Hilty, J. A. \& Merenlender, M. A. (2000). A comparison of covered track-plates and remotely-triggered cameras. Transactions of the Western Section of the Wildlife Society, 36, 27-31. 
Knight, R. L., \& Cole, D. N. (1995). Wildlife responses to recreationists. In Knight, R. L. \& K. J. Gutzwiller, Wildlife and recreationalists: Coexistence through management and research (pp. 51-65). Washington D.C.: Island Press.

Knowles, N., Dettinger, M. D., \& Cayan, D. R. (2006). Trends in snowfall versus rainfall for the Western United States. Journal of Climate, 19, 4545-4559.

Larsen, C. J. (1993). Status review of the riparian brush rabbit (Sylvilagus bachmani riparius) in California. California Department of Fish and Game, Sacramento, Nongame Bird and Mammal, Sec. Rep 93-12.

MacArthur, R. A., Geist, V., \& Johnston, R. H. (1982). Cardiac and behavioral responses of mountain sheep to human disturbance. The Journal of Wildlife Management, $46,351-358$.

MacArthur, R. H. \& Wilson, E. O. (1963). An equilibrium theory of insular zoogeography. Evolution, 17, 373-387.

MacArthur, R. H. \& Wilson, E. O. (1967). The theory of island biogeography. Princeton, NJ: Princeton University Press.

Manning, J. A. \& Edge, W. D. (2004). Small mammal survival and downed wood at multiple scales in managed forests. Journal of Mammalogy, 85, 87-96.

Meckstroth, A. M. \& Miles, A. K. (2005). Predator removal and nesting waterbird success at San Francisco Bay, California. Waterbirds, 28, 250-255.

Miller, N. L., Bashford, K. E., \& Strem, E. (2003). Potential Impacts of Climate Change on California Hydrology. Journal of the American Water Resources Association, $39,771-784$.

Miller, S. G., Knight, R. L., \& Miller, C. K. (1998). Influence of recreational trails on breeding bird communities. Ecological Applications. 8, 162-169.

Meffe, G. \& Carroll, C. (1997). Principles of conservation biology. New York, NY: Sinaur Associates.

Morris, D. W. (1996). Coexistence of specialist and generalist rodents via habitat selection. Ecology, 77, 2352-2364.

National Oceanic \& Atmospheric Administration (2006). Record of climatic observations, Modesto city co ap. Retrieved from http://hurricane.ncdc.noaa.gov/dly/DLY?randomnum=830036174ADMIN. 
Ng, S. J., Dole, J. W., Sauvajot, R. M., Riley, S. P .D., \& Valone, T. J. (2004). Use of highway undercrossings by wildlife in southern California. Biological Conservation, 115, 499-507.

Orr, R. T. (1940). The rabbits of California. Berkeley, CA: Joint contribution from the Museum of vertebrate zoölogy of the University of California and the California academy of sciences

Papouchis, C. M., Singer, F. J., \& Sloanal, W. B. ( 2001). Responses of Desert Bighorn Sheep to Increased Human Recreation. The Journal of Wildlife Management, 65, 573-582.

Rentner, J. \& Lloyd, M. (2010, Summer). Results are in: Endangered rabbits are living in our planted habitats. River Partners Journal, 6(2), 4-5.

Riffell, S. K., Gutzwiller, K. J., \& Anderson, S. H. (1996). Does repeated human intrusion cause cumulative declines in avian richness and abundance? Ecological Applications, 6, 492-505.

Rodgers, C. M. \& Caro, M. J. (1998) Song sparrows, top carnivores, and nest predation: A test of the mesopredator release hypothesis. Oecologia, 116, 227-233.

San Joaquin County Multi-Species Habitat Conservation \& Open Space Plan. (2000). Riparian brush rabbit. Retrieved from http://www.sjcog.org/Programs\%20\&\%20Projects/Habitat_files/Species/Riparian $\% 20$ Brush\%20Rabbit.pdf

Sauvajot, R. M., Buechner, M., Kamradt, D., \& Schoneward, C. (1998). Patterns of human disturbance and response by small mammals and birds in chaparral near urban development. Urban Ecosystems, 2, 279-297.

Schmidt, K. A. (2003). Nest predation and population declines in Illinois songbirds: A case study for mesopredator effects. Conservation Biology, 17, 1141-1150.

Schoenherr, A. A. (1992). A natural history of California. Berkeley, CA: University of California Press.

Stewart, I. T., Cayan D. R., \& Dettinger, M. D. (2003). Changes in snowmelt runoff timing in Western North America under a 'business as usual' climate change scenario. Climatic Change, 62, 217-232.

Taylor, A. R. \& Knight, R. L. (2003). Behavior responses of wildlife to human activity: Terminology and methods. Wildlife Society Bulletin, 31, 1263-1271. 
Thiel, R. P. (1985). Relationship between road densities and wolf habitat suitability in Wisconsin. American Midland Naturalist, 113, 404-407.

U.S. Fish \& Wildlife Service. (1998). Recovery plan for upland species of the San Joaquin Valley, California. Region 1, Portland, OR. 319 pp.

Velazquez, A. \& Heil, G. W. (1996). Habitat suitability study for the conservation of the volcano rabbit (Romerolagus diazi). The Journal of Applied Ecology, 33, 543554.

Whittaker, D. \& Knight, R. L. (1998). Understanding wildlife responses to humans. Wildlife Society Bulletin, 26, 312-317.

Whittington, J., St. Clair, C. C., \& Mercer, G. (2005). Spatial response of wolves to roads and trails in mountain valleys. Ecological Applications, 15, 543-553.

Williams, D.F. (1993). Population censuses of riparian brush rabbits and riparian woodrats at Caswell Memorial State Park during January 1993. Lodi, CA: California Department of Parks and Recreation.

Williams, D. F. \& Basey, G. E. (1986). Population status of the riparian brush rabbit (Sylvilagus bachmani riparius). Sacramento, CA: California Department of Fish and Game.

Williams, D. F., Kelly, P. A., Hamilton, L. P., Lloyd, M. R., Williams, E. A., \& Youngblom, J. L. (2008). Recovering the endangered riparian brush rabbit (Sylvilagus bachmani riparius): Reproduction and growth in confinement and survival after translocation. In Alves, P. C., Ferran, N., \& Hacklader, K., Lagomorph biology: Evolution, ecology, \& conservation. Netherlands: Springer Press.

Williams, D. F. \& Kilburn, K. S. (1984) Sensitive, threatened, and endangered mammals of riparian and other wetland communities in California. In Warner, R. E. \& Hendrix, K. M., California riparian systems: Ecology, conservation, and productive management (pp. 950-956). Berkeley, CA: University of California Press.

Winter, M., Johnson, D. H. \& Faaborg, J. (2000). Evidence for edge effects on multiple levels in tallgrass prairie. The Condor, 102, 256-266.

Yarmoloy, C., Bayer, M., \& Geist, V. (1988). Behavior responses and reproduction of mule deer, Odocoileus hemionus, does following experimental harassment with an all-terrain vehicle. Canadian Field Naturalist, 102, 425-429. 
Zollner, P. A., Smith, W. P. \& Brennan, L. A. (2000). Home range use by swamp rabbits (Sylvilagus aquaticus) in a frequently inundated bottomland forest. American Midland Naturalist, 143, 64-69. 